\title{
2019 Seoul Consensus on Esophageal Achalasia Guidelines
}

\author{
Hye-Kyung Jung, ${ }^{1}$ Su Jin Hong, ${ }^{2}$ Oh Young Lee, ${ }^{3 *}$ John Pandolfino, ${ }^{4}$ Hyojin Park, ${ }^{5}$ Hiroto Miwa, ${ }^{6}$ Uday C Ghoshal, ${ }^{7}$ Sanjiv \\ Mahadeva, ${ }^{8}$ Tadayuki Oshima, ${ }^{6}$ Minhu Chen, ${ }^{9}$ Andrew S B Chua, ${ }^{10}$ Yu Kyung Cho, ${ }^{11}$ Tae Hee Lee, ${ }^{12}$ Yang Won Min, ${ }^{13}$ Chan \\ Hyuk Park, ${ }^{14}$ Joong Goo Kwon, ${ }^{15}$ Moo In Park, ${ }^{16}$ Kyoungwon Jung, ${ }^{16}$ Jong Kyu Park, ${ }^{17}$ Kee Wook Jung, ${ }^{18}$ Hyun Chul Lim, ${ }^{19}$ Da \\ Hyun Jung, ${ }^{20}$ Do Hoon Kim, ${ }^{18}$ Chul-Hyun Lim, ${ }^{21}$ Hee Seok Moon, ${ }^{22}$ Jung Ho Park, ${ }^{23}$ Suck Chei Choi, ${ }^{24}$ Hidekazu Suzuki, ${ }^{25}$ Tanisa \\ Patcharatrakul, ${ }^{26}$ Justin C Y Wu, ${ }^{27}$ Kwang Jae Lee, ${ }^{28}$ Shinwa Tanaka, ${ }^{29}$ Kewin T H Siah, ${ }^{30}$ Kyung Sik Park, ${ }^{31}$ and Sung Eun Kim ${ }^{16} ;$ The \\ Korean Society of Neurogastroenterology and Motility
}

${ }^{1}$ Department of Internal Medicine, Ewha Womans University College of Medicine, Seoul, Korea; ${ }^{2}$ Digestive Disease Center and Research Institute, Department of Internal Medicine, Soonchunhyang University College of Medicine, Bucheon, Korea; ${ }^{3}$ Department of Internal Medicine, Hanyang University Hospital, Hanyang University College of Medicine, Seoul, Korea; ${ }^{4}$ Department of Medicine, Feinberg School of Medicine, Northwestern University, Chicago, IL, USA; ${ }^{5}$ Division of Gastroenterology, Gangnam Severance Hospital, Yonsei University College of Medicine, Seoul, Korea; ${ }^{6}$ Division of Gastroenterology, Department of Internal Medicine, Hyogo College of Medicine, Mukogawa-cho, Nishinomiya, Hyogo, Japan; ${ }^{7}$ Department of Gastroenterology, Sanjay Gandhi Postgraduate Institute of Medical Sciences, Lucknow, India; ${ }^{8}$ Division of Gastroenterology, Department of Medicine, Faculty of Medicine, University of Malaya, Kuala Lumpur, Malaysia; ${ }^{9}$ Department of Gastroenterology and Hepatology, The First Affiliated Hospital of Sun Yat-sen University, Guangzhou, China; ${ }^{10}$ Gastro Centre, Ipoh, Malaysia; ${ }^{11}$ Division of Gastroenterology and Hepatology, Department of Internal Medicine, Seoul St. Mary's Hospital, The Catholic University of Korea, Seoul, Korea; ${ }^{12}$ Department of Internal Medicine, College of Medicine, Soonchunhyang University Hospital, Seoul, Korea; ${ }^{13}$ Department of Medicine, Samsung Medical Center, Sungkyunkwan University School of Medicine, Seoul, Korea; ${ }^{14}$ Department of Internal Medicine, Hanyang University Guri Hospital, Hanyang University College of Medicine, Guri, Korea; ${ }^{15}$ Department of Internal Medicine, Daegu Catholic University School of Medicine, Daegu, Korea, ${ }^{16}$ Department of Internal Medicine, Kosin University College of Medicine, Busan, Korea; ${ }^{17}$ Department of Internal Medicine, Gangneung Asan Hospital, University of Ulsan College of Medicine, Gangneung; Gangwon-do, Korea; ${ }^{18}$ Department of Gastroenterology, Asan Medical Center, University of Ulsan College of Medicine, University of Ulsan College of Medicine, Seoul, Korea; ${ }^{19}$ Department of Internal Medicine, Yongin Severance Hospital, Yonsei University College of Medicine, Yongin, Korea; ${ }^{20}$ Division of Gastroenterology, Department of Internal Medicine, Severance Hospital, Yonsei University College of Medicine, Seoul, Korea; ${ }^{21}$ Department of Internal Medicine, Eunpyeong St. Mary's Hospital, College of Medicine, The Catholic University of Korea, Seoul, Korea; ${ }^{22}$ Department of Internal Medicine, Chungnam National University School of Medicine, Daejeon, Korea; ${ }^{23}$ Division of Gastroenterology, Department of Internal Medicine, Kangbuk Samsung Hospital, Sungkyunkwan University School of Medicine, Seoul, Korea; ${ }^{24}$ Department of Internal Medicine and Digestive Disease Research Institute, Wonkwang University School of Medicine, Iksan, Korea; ${ }^{25}$ Department of Gastroenterology and Hepatology, Tokai University School of Medicine, Isehara, Kanagawa, Japan; ${ }^{26}$ Department of Medicine, King Chulalongkorn Memorial Hospital, Thai Red Cross Society, Bangkok, Thailand; ${ }^{27}$ Department of Medicine and Therapeutics, Prince of Wales Hospital, Hong Kong; China; ${ }^{28}$ Department of Gastroenterology, Ajou University School of Medicine, Suwon, Gyeonggi-do, Korea; ${ }^{29}$ Department of Gastroenterology, Kobe University Hospital, Hyogo, Japan; ${ }^{30}$ Division of Gastroenterology and Hepatology, National University Health System, Singapore City, Singapore; and ${ }^{31}$ Department of Internal Medicine, Keimyung University School of Medicine, Daegu, Korea

Received: January 29, 2020 Revised: None Accepted: March 8, 2020

(a) This is an Open Access article distributed under the terms of the Creative Commons Attribution Non-Commercial License (http://creativecommons. org/licenses/by-nc/4.0) which permits unrestricted non-commercial use, distribution, and reproduction in any medium, provided the original work is properly cited.

*Correspondence: Oh Young Lee, MD, PhD

Department of Internal Medicine, Hanyang University College of Medicine, 222 Wangsimni-ro, Seongdong-gu, Seoul 04763, Korea Tel: +82-2-2290-8343, Fax: +82-2-2298-8341, E-mail: leeoy@hanyang.ac.kr

Hye-Kyung Jung and Su Jin Hong equally contributed to this study. 
Esophageal achalasia is a primary motility disorder characterized by insufficient lower esophageal sphincter relaxation and loss of esophageal peristalsis. Achalasia is a chronic disease that causes progressive irreversible loss of esophageal motor function. The recent development of high-resolution manometry has facilitated the diagnosis of achalasia, and determining the achalasia subtypes based on high-resolution manometry can be important when deciding on treatment methods. Peroral endoscopic myotomy is less invasive than surgery with comparable efficacy. The present guidelines (the "2019 Seoul Consensus on Esophageal Achalasia Guidelines") were developed based on evidence-based medicine; the Asian Neurogastroenterology and Motility Association and Korean Society of Neurogastroenterology and Motility served as the operating and development committees, respectively. The development of the guidelines began in June 2018, and a draft consensus based on the Delphi process was achieved in April 2019. The guidelines consist of 18 recommendations: 2 pertaining to the definition and epidemiology of achalasia, 6 pertaining to diagnoses, and 10 pertaining to treatments. The endoscopic treatment section is based on the latest evidence from meta-analyses. Clinicians (including gastroenterologists, upper gastrointestinal tract surgeons, general physicians, nurses, and other hospital workers) and patients could use these guidelines to make an informed decision on the management of achalasia.

(J Neurogastroenterol Motil 2020;26:180-203)

\section{Key Words}

Esophageal achalasia; Esophageal motility disorders; Guideline; Manometry; Myotomy

\section{Introduction}

Esophageal achalasia is a primary motility disorder characterized by incomplete lower esophageal sphincter (LES) relaxation and loss of esophageal peristalsis. ${ }^{1}$ Consequently, the transit of swallowed food boluses through the esophagus is impaired and the patient typically experiences dysphagia. Backflow of saliva or undigested food can cause heartburn, regurgitation or vomiting, chest pain, and respiratory symptoms such as nocturnal cough, recurrent breathing difficulty, and pneumonia. Achalasia is a chronic disease that causes progressive irreversible loss of esophageal motor function. Achalasia is difficult to diagnose early, but it is important to identify and treat the condition before irreversible changes occur.

Over the last decade, novel diagnostic modalities, such as high-resolution manometry (HRM), as well as treatment advances such as peroral endoscopic myotomy (POEM), have greatly improved the success rate of achalasia treatment. However, these developments remain unknown to most but few gastrointestinal (GI) motility experts. We need clinical guidelines for the diagnosis and management of achalasia based on evidence-based medicine that will help to inform healthcare providers and patients.

The guidelines describe approaches to the practical management of adult patients with achalasia based on scientific evidence and expert consensus. The guidelines cover several options for the treatment of achalasia, summarize the benefits and harms of each, and provide information on the probable outcomes.

The present guidelines provide a practical, evidence-based guide for clinicians (gastroenterologists, upper GI tract sur- geons, and general physicians), nurses, and paramedical teams. The guidelines are intended to help primary physicians and general health professionals to make achalasia management decisions; the guidelines are also designed to provide educational resource for medical students and healthcare providers, and to provide patients with the most up-to-date information on their conditions.

\section{Methods}

The guideline steering committee consisted of the Presidents and key members of the Korean Society of Neurogastroenterology and Motility (KSNM) and Asian Neurogastroenterology and Motility Association (ANMA). This committee established the guideline development strategy and approved the project budget. Development of the guidelines began in June 2018. The working group comprises 38 expert gastroenterologists, surgeons and methodologists, selected from among KSNM and ANMA members and other experts. Three workshops were conducted while developing the revised guidelines and the working group held 8 meetings.

The working group identified the most clinically significant questions using the nominal group technique. ${ }^{2}$ The guidelines were developed using both adaptation and de novo methods. The literature was searched for existing guidelines on achalasia. The search terms used were achalasia-related index words ("achalasia") and guideline-related index words ("clinical protocols" OR "indication" OR "therapeutics" OR "therapy" OR "therapeutic use" OR "therapy*” OR "diagnosis" OR "guideline" OR "guidelines as topic" OR "guideline adherence" OR "practice guideline" OR 
"practice guideline as topic" OR "clinical guideline" OR "clinical practice guideline" OR "consensus" OR "recommendation" OR "workshop"). The inclusion criteria for the existing guidelines were as follows: (1) achalasia guidelines pertaining to adults, (2) written in English, and (3) published between January 2005 and July 2018. The exclusion criteria were as follows: (1) already developed via the adaptation process and (2) not supported by evidence-based medicine. Eight guidelines were identified. A systematic review was also conducted, to identify clinical recommendations requiring an update due to new evidence, particularly pertaining to POEM and laparoscopic Heller myotomy (LHM). The Medline, EMBASE, and Cochrane Library databases were searched for all relevant studies published during the period 2000-2018. The following index terms were used as search queries: ([POEM] OR [endoscopic myotomy]) AND ([laparoscopic myotomy] OR [surgical myotomy] OR [Heller myotomy] or [Heller's myotomy]). The inclusion criteria were as follows: (1) published in English, (2) published between 2000 and 2018, and (3) pertaining to adult patients with achalasia. The exclusion criteria were as follows: (1) published in languages other than English, (2) animal studies, and (3) studies of adolescents or children (under the age of 19 years) (Supplementary Figure). We critically appraised the quality of the selected studies using the risk of bias tools described in the endoscopic treatment section developed by a de novo method and the Cochrane Risk of Bias Tool. ${ }^{3}$ The level of evidence for achalasia treatment recommendation was assessed based on the Grading of Recommendations, Assessment, Development and Evaluation (GRADE) system (Table 1). ${ }^{4}$ The treatment recommendations for primary esophageal achalasia were classified as "strong for" "weak for" "weak against" "strong against" or "no recommendation". The evidence level, clinical applicability, and benefits and harms were the evaluation criteria.

Consensus was sought for the draft recommendations developed herein using the modified Delphi method. ${ }^{5}$ An expert panel comprising members of the KSNM and ANMA, and other experts, reviewed the draft. The first draft consisted of 18 recommendations with one open question: 2 pertaining to the definition and epidemiology of achalasia, 6 pertaining to diagnoses, and 10 pertaining to treatments. The first draft was sent via e-mail to the experts and their responses were anonymized. A score of more than 4 on a 5-point Likert scale was considered to correspond to "agree" (with the recommendation in question); if more than two-thirds of all 47 respondents agreed with a recommendation, consensus was considered to have been reached thereon. Consensus was not reached on only 1 of the 18 recommendations on LHM. After the first round of appraisals, the working group presented the draft recommendations at an ANMA consensus meeting held on April 6, 2019. A second round of appraisals, of the modified recommendation for LHM, achieved a $93.9 \%$ consensus (31/33 experts). Two

Table 1. Levels of Evidence and Support for the Various Primary Esophageal Achalasia Treatment Recommendations ${ }^{4}$

\begin{tabular}{|c|c|}
\hline \multicolumn{2}{|l|}{ Level of evidence } \\
\hline High & At least one $\mathrm{RCT}$ or SR/meta-analysis with no concern regarding study quality \\
\hline Moderate & $\begin{array}{l}\text { At least one } \mathrm{RCT} \text { or } \mathrm{SR} / \text { meta-analysis with minor concerns regarding study quality or, } \\
\text { at least one cohort/case-control/diagnostic test design study with no concern regarding study quality }\end{array}$ \\
\hline Low & $\begin{array}{l}\text { At least one cohort/case-control/diagnostic test study with minor concerns regarding study quality, } \\
\text { or at least one single arm before-after study or, cross-sectional study with no concerns regarding study quality }\end{array}$ \\
\hline Very low & $\begin{array}{l}\text { At least one cohort/case-control/diagnostic test design study with serious concerns regarding study quality, } \\
\text { or at least one single arm before-after study or cross-sectional study with minor/severe concerns regarding study quality }\end{array}$ \\
\hline \multicolumn{2}{|c|}{ Grade of recommendation } \\
\hline Strong for & $\begin{array}{l}\text { The benefits of the intervention are greater than the harms based on a high or moderate level of evidence, } \\
\text { such that it can be strongly recommended for clinical practice in most cases. }\end{array}$ \\
\hline Weak for & $\begin{array}{l}\text { The benefits and harms of the intervention may vary depending on the clinical situation or patient characteristics. } \\
\text { Recommended depending to the clinical situation. }\end{array}$ \\
\hline Weak against & $\begin{array}{l}\text { The benefits and harms of the intervention may vary depending on the clinical situation or patient characteristics. } \\
\text { Intervention not be recommended for clinical practice. }\end{array}$ \\
\hline Strong against & $\begin{array}{l}\text { The harms of the intervention are greater than the benefits based on a high or moderate level of evidence, } \\
\text { such that it is not recommended for clinical practice. }\end{array}$ \\
\hline No recommendation & $\begin{array}{l}\text { It is not possible to classify the recommendation owing to a lack of evidence or equivocal results. } \\
\text { Further evidence is needed. }\end{array}$ \\
\hline
\end{tabular}

$\mathrm{RCT}$, randomized controlled trial; SR, systematic review. 
external experts (Y.T.B. [South Korea] and S.G [Thailand] reviewed the recommendations in terms of necessity, appropriateness, health care setting, level of care, and balance between benefits and harms. The final 18 recommendations/guidelines, and a flowchart for the diagnosis and treatment of esophageal achalasia, are presented in Table 2 and Figure 1, respectively.

This project was funded by the KSNM; there was no external source of support. All members of the working team confirmed via e-mail that they had no conflicts of interest related to the development of the guidelines, which will be updated every 3 to 5 years to take account of new evidences accumulated.

\section{Definition and Epidemiology of Achalasia -}

\section{Definition}

\section{Statement 1: Achalasia is a primary motor disorder of the esophagus characterized by insufficient lower esophageal sphincter relaxation and loss of esophageal peristalsis.}

(Level of evidence, not applicable; strength of recommendation, not applicable)

Experts' opinions: agree strongly (78.2\%), agree with some reservations $(19.6 \%)$, undecided $(0.0 \%)$, disagree $(2.2 \%)$, and disagree strongly $(0.0 \%)$
Achalasia is a primary esophageal motor disorder characterized by incomplete LES relaxation and an absence of esophageal peristalsis. ${ }^{1}$ The cause of achalasia is not clear yet. Idiopathic achalasia occurs secondary to destruction of the myenteric plexus, which involves both peristaltic contraction and LES relaxation. ${ }^{6}$ The clinical presentation includes dysphagia to solids and liquids, regurgitation of bland undigested food or saliva, chest pain during eating, and weight loss. Objective symptom scoring systems, such as the Eckardt score, are important for determining the treatment response (Table 3). ${ }^{1}$ A subset of patients with achalasia experience heartburn, which often leads to misdiagnosis of achalasia as gastroesophageal reflux disease (GERD). ${ }^{7}$ Achalasia can be diagnosed based on manometry, esophagography, or endoscopy findings. ${ }^{1}$ Pseudoachalasia, which shows similar clinical features but is caused by cancer or Trypanosoma cruzi infection, should be excluded. ${ }^{8}$

\section{Epidemiology of Achalasia}

\section{Statement 2: Achalasia is a very rare disorder of the esophagus that affects both sexes equally and is fre-} quently diagnosed in patients aged 40 to 60 years.

(Level of evidence, not applicable; strength of recommendation, not applicable)

Experts' opinions: agree strongly (34.8\%), agree with some reservations $(54.4 \%)$, undecided $(6.5 \%)$, disagree $(4.3 \%)$, and disagree strongly $(0.0 \%)$

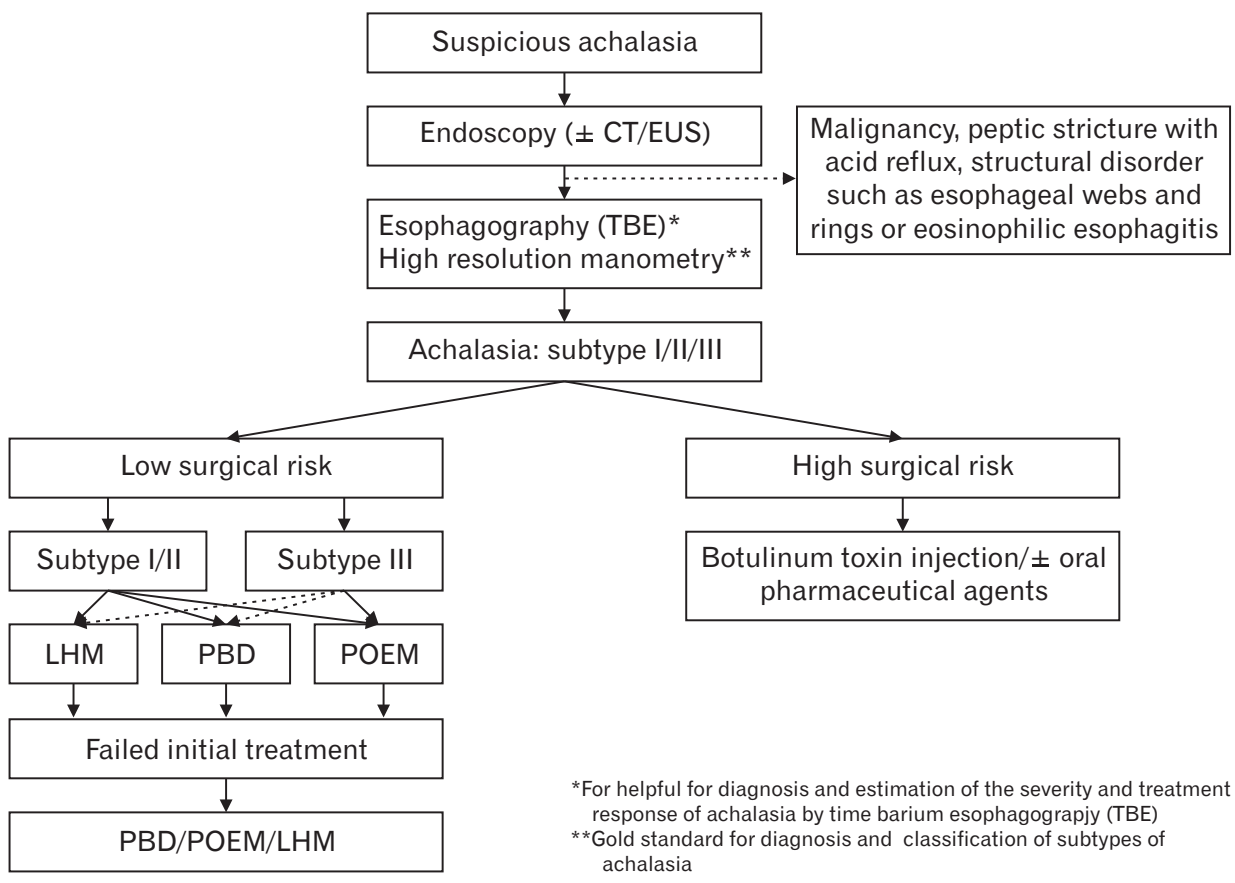

Figure 1. Flowchart of the management of esophageal achalasia. CT, computed tomography; EUS, endoscopic ultrasonography; LHM, laparoscopic Heller myotomy; PBD, pneumatic balloondilatation; POEM, peroral endoscopic myotomy. 
Table 2. Summary of Recommendations/Guidelines for Primary Esophageal Achalasia

Definition and epidemiology of achalasia

1. Achalasia is a primary motor disorder of the esophagus characterized by insufficient lower esophageal sphincter relaxation and loss of esophageal peristalsis.

2. Achalasia is a very rare disorder of the esophagus that affects both sexes equally and is frequently

NA

diagnosed in patients aged between 40 and 60 years.

Diagnosis of esophageal achalasia

Esophageal manometry

3. Esophageal manometry is a gold standard test for diagnosis of achalasia.

4. High-resolution manometry is superior to conventional manometry for the diagnosis of achalasia.

5. The Chicago classification is a useful tool to define the clinically relevant phenotypes of achalasia.

Barium esophagography

6. Barium esophagography is recommended to diagnose achalasia in patients with esophageal dysphagia.

7. Timed barium esophagography is useful for assessing the severity of achalasia, and for evaluating treatment outcomes.

Endoscopy

8. Endoscopic assessment is recommended for achalasia patients to rule out pseudoachalasia caused by cancer or other esophageal diseases (eg, peptic stricture with acid reflux, structural disorders such as esophageal webs and rings, or esophageal inflammation).

Treatment of esophageal achalasia

Oral pharmacologic treatment

9. Oral pharmacologic therapy can be considered for achalasia whose general condition renders them unsuitable for endoscopic treatment or surgery.

Botulinum toxin injection

10. Botulinum toxin injection is recommended for achalasia patients whose general condition renders them unsuitable for endoscopic treatment or surgery.

Pneumatic balloon dilatation

11. Pneumatic balloon dilatation is recommended as an initial treatment for patients with achalasia.

Peroral endoscopic myotomy

12. The outcomes of peroral endoscopic myotomy are comparable to those of Heller myotomy for treatment-naïve patients with achalasia.

13. Peroral endoscopic myotomy, rather than Heller myotomy, should be considered for the treatment of type III achalasia because enables extended myotomy.

14. Acid suppressive therapy is recommended for patients with reflux symptoms or esophageal erosion undergoing peroral endoscopic myotomy, to prevent esophageal stricture.

Surgical treatment

15. Laparoscopic Heller myotomy can be considered as one of first-line therapies for achalasia patients, and has similar expected clinical outcomes to pneumatic balloon dilation.

16. Partial fundoplication in addition to LHM is recommended to reduce the risk of subsequent GERD.

Management of recurrence of achalasia after initial treatment

17. Peroral endoscopic myotomy is recommended for achalasia patients who failed initial endoscopic treatment.

18. Peroral endoscopic myotomy can be considered as a rescue treatment for achalasia patients. who were not treated successfully by laparoscopic Heller's myotomy.

$\begin{array}{ll}\text { Low } & \text { Strong } \\ \text { Low } & \text { Strong } \\ \text { Moderate } & \text { Strong } \\ & \\ \text { Low } & \text { Strong } \\ \text { Moderate } & \text { Strong }\end{array}$

Low Strong

Low

Weak

Moderate

Strong

Moderate

Strong

Moderate

Strong

Low

Weak

Low

Strong

Moderate

Weak

Low

Strong

Moderate

Strong

Low

NA, not applicable; LHM, laparoscopic Heller myotomy; GERD, gastroesophageal reflux disease.

Achalasia is a rare esophageal motility disorder. Populationbased epidemiological data on achalasia are sparse and most existing studies used a retrospective design. ${ }^{9}$ According to studies conducted in the 2000s, the incidence of achalasia is increasing and does not differ according to ethnicity. The incidence of achalasia is $0.03-0.27$ per 100000 persons per year in developing countries (Fig. 2). ${ }^{10,11} \mathrm{~A}$ recent large cohort study based on Dutch healthcare insurance data revealed an incidence of achalasia of 2.2 per 100000 persons per 
Table 3. Eckardt Score for Clinical Classification of Achalasia Severity

\begin{tabular}{cllll}
\hline Score & Dysphagia & Regurgitation & Retrosternal pain & Weight loss $(\mathrm{kg})$ \\
\hline 0 & None & None & None & None \\
1 & Occasional & Occasional & Occasional & 5 \\
2 & Daily & Daily & Daily & $5-10$ \\
3 & Each meal & Each meal & Each meal & $>10$ \\
\hline
\end{tabular}

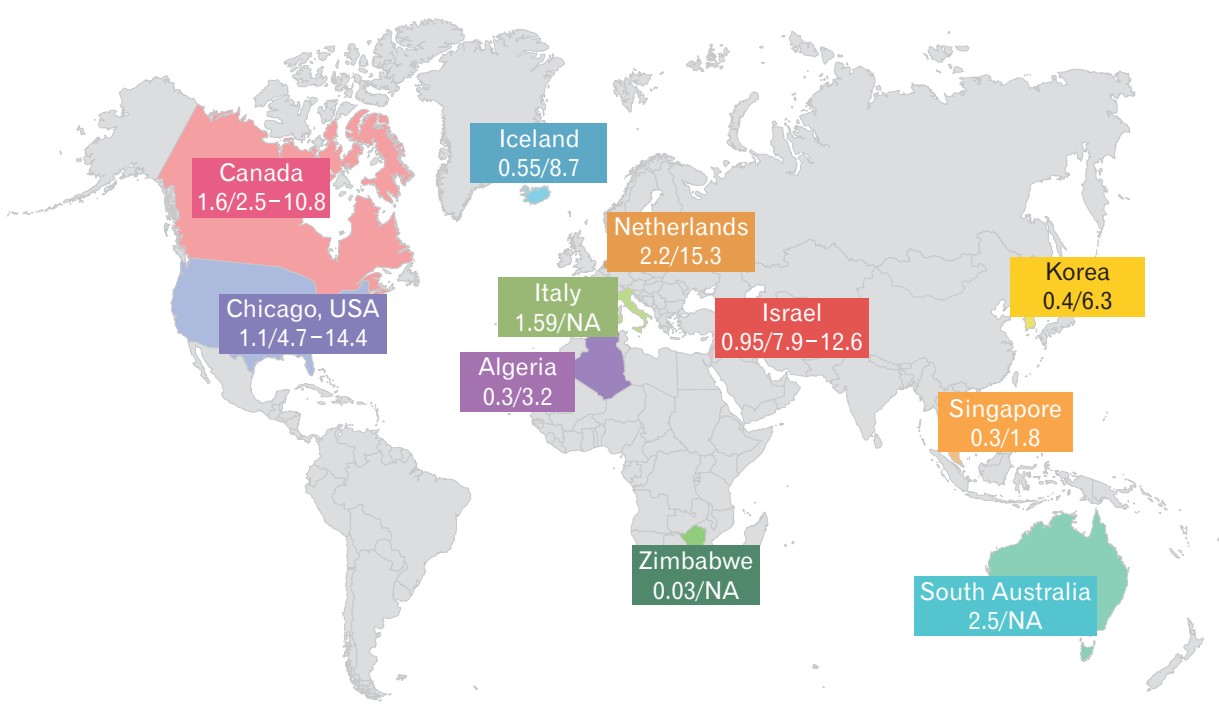

Figure 2. Reported incidence and prevalence rates of achalasia. Data are expressed as rates per 100000 persons per year (incidence/prevalence).

year, ${ }^{9}$ compared to 2.9 per 100000 persons in a study using tertiary hospital data. ${ }^{12}$ The prevalence of achalasia also appears to be increasing slightly. A Dutch study reported a prevalence rate of 15.3 per 100000 persons, ${ }^{9}$ and other studies have reported prevalence rates of 2.5-32.6 per 100000 persons. ${ }^{12,13}$ However, Kim et $\mathrm{al}^{14}$ reported that the incidence and prevalence of achalasia were 0.4 and 6.3 per 100000 persons, respectively, in population-based studies based on a Korean national healthcare database.

The numbers of male and female patients with achalasia were similar in several large-scale epidemiological studies. ${ }^{9,11,14,15}$ Although achalasia can occur at any age, it is most prevalent in patients aged 40 to 60 years. ${ }^{9,11,16}$ Asian epidemiological studies have reported similar data to Western studies.

\section{Diagnosis of Achalasia}

\section{Esophageal Manometry}

Esophageal manometry is essential for assessing esophageal motor function in patients with achalasia. ${ }^{1}$ Barium esophagography and esophagogastroduodenoscopy (EGD) are used as comple- mentary tests to manometry in the diagnosis and management of achalasia. ${ }^{17,18}$ However, neither EGD nor barium esophagography alone is sensitive enough to achieve a definitive diagnosis. EGD can be used as a supportive tool for diagnosis of achalasia in only one-third of patients, and esophagography in up to two-thirds of patients. Thus, patients suspected to have achalasia but who have shown normal results in EGD or esophagography studies must undergo esophageal motility tests. However, in patients with EGD or esophagography findings typical of achalasia, esophageal motility tests should be performed to confirm the diagnosis.

\section{Statement 3: Esophageal manometry is a gold standard test for the diagnosis of achalasia.}

(Level of evidence, low; strength of recommendation, strong)

Experts' opinions: agree strongly (76.1\%), agree with some reservations $(23.9 \%)$, undecided $(0.0 \%)$, disagree $(0.0 \%)$, and disagree strongly $(0.0 \%)$

Manometric findings of aperistalsis and incomplete LES relaxation without evidence of mechanical obstruction supports the diagnosis of achalasia (Fig. 3A). Other findings, such as increased 
A

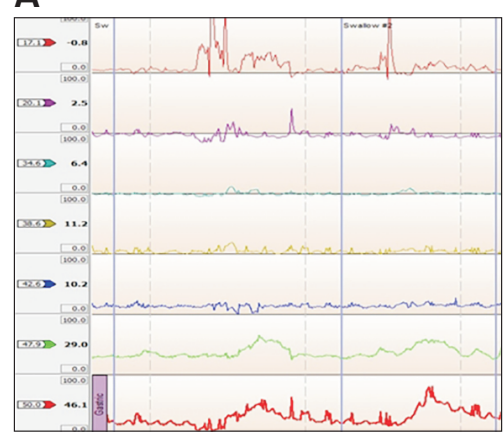

B

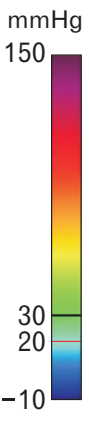

Achalasia type I

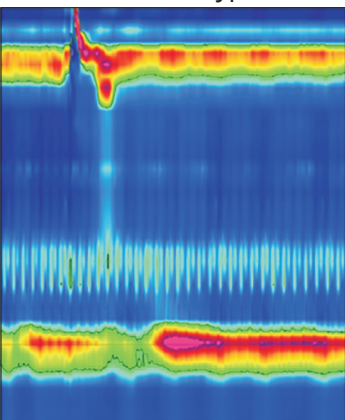

Achalasia type II

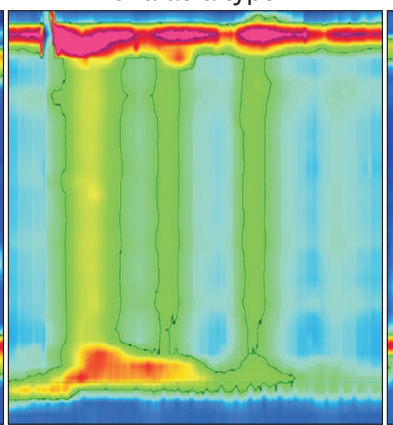

Achalasia type III

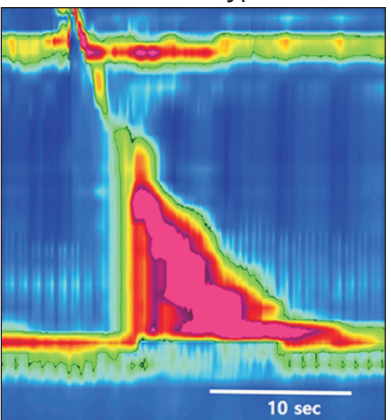

Figure 3. Manometric findings of esophageal achalasia. A. Conventional esophageal manometry findings of achalasia. Achalasia is characterized by incomplete lower esophageal sphincter (LES) relaxation upon deglutition, defined as a residual pressure $>10 \mathrm{mmHg}$, and aperistalsis in the body of the esophagus. In addition, the resting tone of the LES will often be elevated. B. Subtypes of esophageal achalasia identified by high-resolution manometry: type I, classic achalasia with no evidence of pressurization; type II, panesophageal pressurization; and type III, vigorous achalasia or spastic contractions of the distal esophageal segment.

basal LES and baseline esophageal body pressure with simultaneous non-propagating contractions, are also suggestive of achalasia, but are not required for its diagnosis. Though rare, variants of achalasia differing in the degree of incomplete LES relaxation and aperistalsis, as well as some characterized by complete LES relaxation, have been described. ${ }^{19}$ Aperistalsis has been defined as a lack of esophageal body peristalsis and can present with different pressure patterns, such as a "quiescent" esophageal body, isobaric panesophageal pressurization, and simultaneous contractions. Achalasia variants presenting with propagating contractions, which could represent either early achalasia or, most commonly, a subclinical mechanical obstruction at the esophago-gastric junction, have also been described. This heterogeneity demonstrates the need for motility studies, where motor patterns can affect diagnosis and management.

\section{Statement 4: High-resolution manometry is superior to conventional manometry for the diagnosis of achalasia.}

(Level of evidence, low; strength of recommendation, strong)

Experts' opinions: agree strongly (71.8\%), agree with some reservations $(23.9 \%)$, undecided $(4.3 \%)$, disagree $(0.0 \%)$, and disagree strongly $(0.0 \%)$

Data are emerging suggesting that HRM may have greater sensitivity for diagnosing achalasia than conventional manometry. ${ }^{20}$ Conventional manometric techniques and tracing analysis (interval of 3-5 cm) can be utilized to depict the pressure profile of the smooth muscle esophagus; however, with HRM, the whole esophagus can be analyzed, which is useful for predicting not only the presence of achalasia, but also the treatment response. Esophageal pressure topography enables the differentiation of achalasia into 3 subtypes, which has implications for treatment outcomes. ${ }^{20}$ Although these achalasia subtypes can be defined by careful analysis of conventional tracings, they can be distinguished more easily and reproducibly by $\mathrm{HRM}^{21}$

\section{Statement 5: The Chicago classification is useful for defining the clinically relevant phenotypes of achalasia.}

(Level of evidence, moderate; strength of recommendation, strong)

Experts' opinions: agree strongly (50.0\%), agree with some reservations $(45.7 \%)$, undecided $(4.3 \%)$, disagree $(0.0 \%)$, and disagree strongly $(0.0 \%)$

Based on the relaxation pressure and propagation and pressurization parameters, the Chicago classification 3.0 is a system for classifying achalasia into distinct subtypes (I-III) and variants, ie, early achalasia with esophagogastric junction (EGJ) outflow obstruction (EGJOO) and achalasia associated with hypotonic LES (absence of contractility) (Fig. 3B). ${ }^{19-21}$ Type I achalasia, called classic achalasia, is characterized by an absence of esophageal body smooth muscle contractility and no esophageal pressurization. These findings are more typical of late-stage achalasia, in which there is loss of muscle tone and subsequent dilation of the esophageal body. Type II achalasia, which is the most common type, is characterized by periods of esophageal pressure and compression; the smooth muscle of the esophagus retains its tone and there is absent peristalsis with abnormal pan-esophageal high-pressure patterns. If $20.0 \%$ or more of the patient's swallows are characterized by this panesophageal pressurization, the achalasia is classified as type II. Type III achalasia, which is the least common type, is characterized by spastic 
contraction of the distal esophagus in at least $20.0 \%$ of swallows.

The achalasia subtypes have been linked to the treatment response in multiple studies, including a recent systematic review and meta-analysis of manometric findings. ${ }^{22}$ These findings should be used to guide treatment decisions. Multiple studies have reported different treatment success rates among the 3 achalasia subtypes, particularly, type III showing a higher likelihood of treatment failure compared to type II achalasia. ${ }^{22,23}$ The inferior response of type III patients is often attributed to spastic contractions in the esophageal body. Pratap and colleagues found that type II predicted a good response to pneumatic dilatation. ${ }^{24}$ The European Achalasia Trial showed that treatment success rates for type II achalasia were high for both LHM (93.0\%) and pneumatic balloon dilation (PBD; $100.0 \%) .^{25}$ The follow-up data of the same trial confirmed that type III achalasia is indeed an important predictor of treatment failure, at least for PBD. Studies of LHM also found type III achalasia to be predictive of a poor treatment outcome. Patients with type III achalasia had the highest incidence of failure $(22.2 \%$ vs $3.0 \%$ and $3.4 \%$ for types I and type II, respectively; $P=0.01){ }^{26-28}$ Finally, four studies reported that type III achalasia was associated with failure of POEM treatment. ${ }^{23,29-31}$

\section{Barium Esophagography}

Statement 6: Barium esophagography is recommended to diagnose achalasia in patients with esophageal dysphagia.
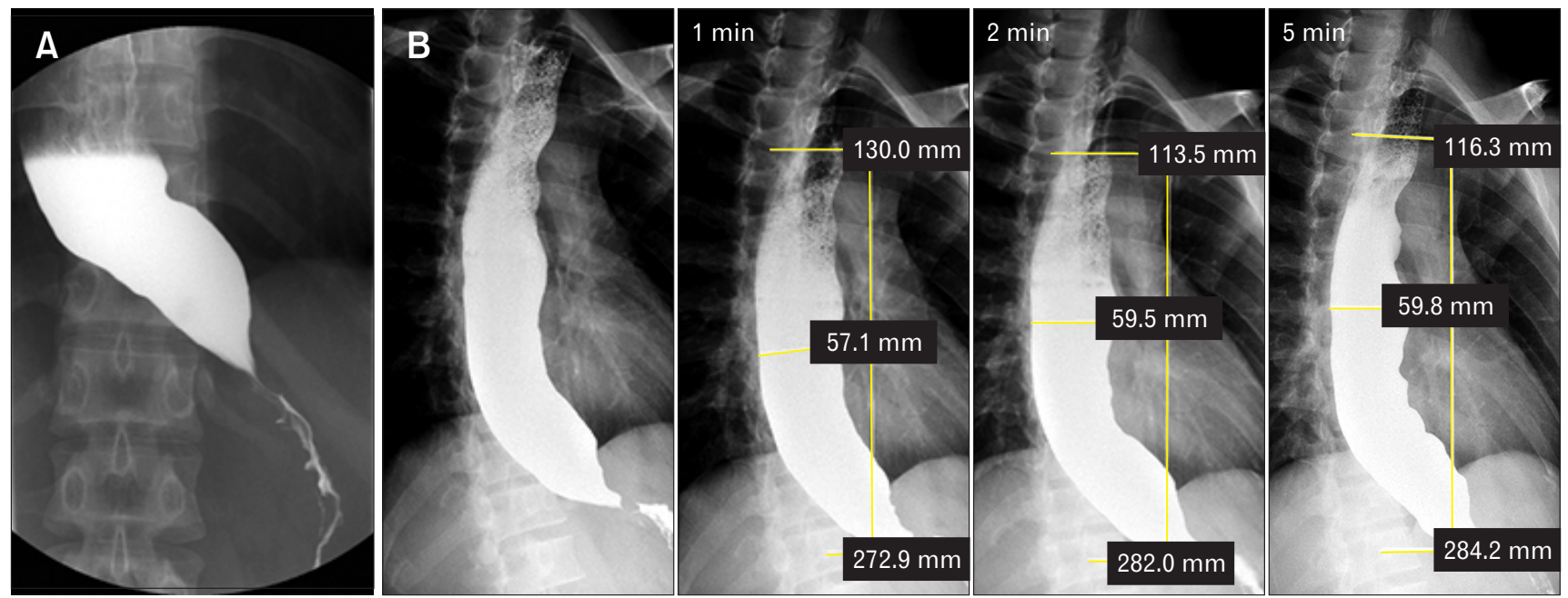

Figure 4. Esophagographic findings of esophageal achalasia. A. Barium swallow typically reveals a "bird-beak" appearance of the esophagogastric junction, with a dilated esophageal body and an air-fluid level in the absence of an intragastric air bubble, or even a sigmoid-like appearance (in advanced cases). B. Timed barium esophagography for measuring esophageal emptying at 1,2, and 5 minutes. The barium column height is measured from the end of the esophagus. 
the patient in the upright position. The patient is instructed to drink $100-250 \mathrm{~mL}$ of low-density barium and the barium column height is measured from the end of the esophagus; the height at 5 minutes is used to determine the completeness of emptying. ${ }^{34}$ TBE predicts the likelihood of symptom recurrence after PD or surgical myotomy. ${ }^{35}$ Rohof et $\mathrm{al}^{34}$ found that esophageal retention was a good predictor of treatment failure in cases of long-standing achalasia and proposed basing the decision for retreatment on the TBE rather than manometry. Moreover, studies using TBE showed that it improved diagnosis and prediction of treatment outcome. In a recent study including achalasia patients, and those with EGJOO or dysphagia of other origin, a barium column height of $5 \mathrm{~cm}$ after 1 minute showed the highest sensitivity and specificity (of $94.0 \%$ and $71.0 \%$, respectively) for differentiating untreated achalasia from EGJOO and nonachalasia based on receiver operating characteristic analysis. ${ }^{36}$

\section{Endoscopy}

\section{Statement 8: Endoscopic assessment is recommended for achalasia patients to rule out pseudoachalasia caused by cancer and other esophageal diseases (eg, peptic stricture with acid reflux, structural disorders such as esophageal webs and rings, or esophageal in- flammation).}

(Level of evidence, low; strength of recommendation, strong)

Experts' opinions: agree strongly (78.2\%), agree with some reservations $(19.6 \%)$, undecided $(2.2 \%)$, disagree $(0.0 \%)$, and disagree strongly $(0.0 \%)$

EGD has a low diagnostic yield for achalasia; its primary role is exclusion of mechanical obstruction secondary to a peptic stricture or cancer in patients with dysphagia. ${ }^{16}$ EGD can also rule out reflux esophagitis, structural lesions (strictures, webs, or rings), and eosinophilic esophagitis. A tumor infiltrating the gastroesophageal junction and cardia can mimic the clinical, radiological, and manometric findings of achalasia, resulting in impaired LES relaxation, esophageal dilatation, and absence of peristalsis. This condition is defined as "secondary achalasia" or "pseudoachalasia." Similar to the manometric features of achalasia, mechanical obstruction can result in both impaired EGJ relaxation and abnormal esophageal body function (aperistalsis or spastic contractions).

Dysphagia to solids and liquids, short-duration dysphagia $(<1$ year), serious weight loss ( $>6.8 \mathrm{~kg})$, and age over 55 years should lead to suspicion of secondary achalasia; however, these signs are neither sensitive nor specific. ${ }^{37}$ Thus, in patients with HRM or esophagography findings of achalasia, endoscopic evaluation of the EGJ and cardia is needed to ensure that there is no infiltration of cancer. Mucosal ulceration or nodularity, reduced compliance of the EGJ, or an inability to pass the endoscope into the stomach are the most common endoscopic findings of pseudoachalasia. Endoscopic mucosal biopsy is used to diagnose secondary pseudoachalasia. When biopsy is negative but secondary achalasia is suspected, computed tomography or endoscopic ultrasonography can help to rule out pseudoachalasia. ${ }^{38,39}$

In idiopathic achalasia, the endoscopic findings at the EGJ range from normal-appearing (in about $40 \%$ of patients) to a thickened muscular ring that may have a rosette configuration on retroflexion, accompanied by signs of esophagitis such as friability, thickening, and even erosion secondary to food stasis (Fig. 5), as well as mild-to-moderate resistance to intubation of the EGJ. ${ }^{40}$ Saliva, liquid, and undigested food material may be seen in the esophagus in the absence of mucosal abnormality or tumor. ${ }^{1}$ As the disease progresses, luminal dilation and tortuosity make the diagnosis more obvious. ${ }^{41,42}$ Although endoscopy may suggest achalasia, other tests must be performed to confirm the diagnosis.

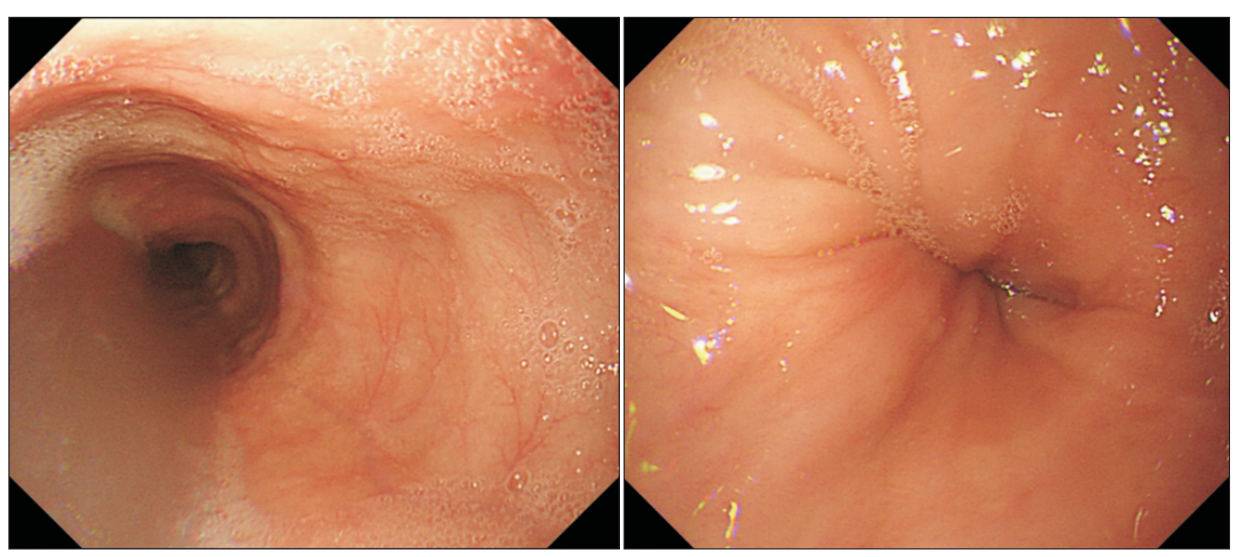

Figure 5. Endoscopic findings of esophageal achalasia. A dilated esophagus showing food stasis, saliva and some resistance at the gastroesophageal junction. 


\section{Treatment of Esophageal Achalasia}

The goal of achalasia treatment is to promote relief of dysphagia and related complications. Several treatments can be tailored according to the patient's overall health status. However, there is no specific therapy targeting the underlying disease process, because the pathogenesis of the impaired esophageal peristalsis and poor esophageal sphincter relaxation are unclear:

PBD, POEM, and LHM provide similarly effective longterm results for esophageal achalasia. In patients whose condition is too poor for endoscopic treatment or surgery, botulinum injection or oral medication might be helpful.

\section{Oral Pharmacologic Treatment}

\section{Statement 9: Oral pharmacologic therapy can be con- sidered for achalasia patients whose medical condition is unsuitable for endoscopic treatment or surgery.}

(Level of evidence, low; strength of recommendation, weak)

Experts' opinions: agree strongly (21.8\%), agree with some reservations (50\%), undecided (21.8\%), disagree (6.5\%), and disagree strongly $(0.0 \%)$

Uncontrolled and small studies reported that a number of pharmacological agents, including calcium channel blockers, nitrates, anticholinergics, phosphodiesterase inhibitors, and $\beta$-adrenergic agonists, have been used for treating achalasia. These agents are effective in reducing LES pressure and temporarily relieving dysphagia, but do not improve LES relaxation or peristalsis. ${ }^{43}$ Calcium channel blockers transiently decrease LES pressure by 13.0-49.0\%, facilitate esophageal emptying and improve symptom severity by $0.0-77.0 \%{ }^{44-47}$ Calcium channel blockers are associated with side effects, such as headache, hypotension, and peripheral edema. ${ }^{48}$ Anticholinergics (eg, cimetropium bromide) decrease LES pressure and accelerate esophageal transit. A double-blind, placebo-controlled trial showed that cimetropium bromide reduced LES pressure by $70.0 \%$ for about 45 minutes, and improved esophageal transit. ${ }^{49}$ The clinical response to pharmacologic agents is short-lived; they do not provide complete relief of symptoms and efficacy decreases substantially over time. ${ }^{45}$ Thus, these agents are commonly reserved for patients who cannot, or refuse to, undergo endoscopic or surgical therapy, and for those who have failed endoscopic or surgical therapy.

\section{Botulinum Toxin Injection}

\section{Statement 10: Botulinum toxin injection is recom- mended for achalasia patients whose medical condition is unsuitable for endoscopic treatment or surgery.}

(Level of evidence, moderate; strength of recommendation, strong)

Experts' opinions: agree strongly (42.5\%), agree with some reservations (42.5\%), undecided (10.7\%), disagree (4.3\%), and disagree strongly $(0.0 \%)$

Injection of botulinum toxin into the LES has been shown to improve the symptoms of achalasia (dysphasia, regurgitation, and chest pain), decrease the LES pressure, improve esophageal emptying, and increase the size of the LES aperture compared to injection of placebo (Table 4). ${ }^{50,51}$ However, although multiple trials have demonstrated short-term benefits of botulinum toxin injection, a single injection of botulinum toxin has only short-duration clinical effects with relapses within several months occurring frequently. ${ }^{51-59}$

Typically, $100 \mathrm{U}$ of botulinum toxin is injected into 4 quadrant of LES each as 4 divided doses. There is wide variability in the timing of the botulinum toxin injections. A multicenter randomized study found no clear dose-response effect (doses of 50, 100, or 200 $\mathrm{U})$ after 1 month, but 2 injections of $100 \mathrm{U}$ botulinum toxin, 30 days apart, was the most effective therapeutic schedule. ${ }^{60}$ According to a 9-year retrospective chart review, botulinum toxin was used in $21.0 \%$ of achalasia patients. Symptom improvement persisted for a mean of 6.2 months, with a need for repeated injections (mean, 1.7; range: $1-7$ ), and about $43.0 \%$ of patients required different, additional treatments. ${ }^{61}$

Botulinum toxin injection can induce esophageal perforation or, inflammatory mediastinitis ${ }^{62}$ and chest pain (4.3\%) or heartburn $(0.7 \%),{ }^{58}$ but it is a relatively safe treatment because of the low probability of complications. Botulinum toxin injection is less efficacious than PBD and myotomy in inducing long-term remission of achalasia. ${ }^{51,63}$ However, if myotomy or PBD cannot be performed because the patient is in poor general condition, repeated botulinum toxin injection should be considered. Following repeated botulinum toxin injection, $50.0 \%$ of patients were asymptomatic. The median duration of the symptom-free period was 11.5 months after the first botulinum injection, and 10.5 months after the second. ${ }^{63}$ 


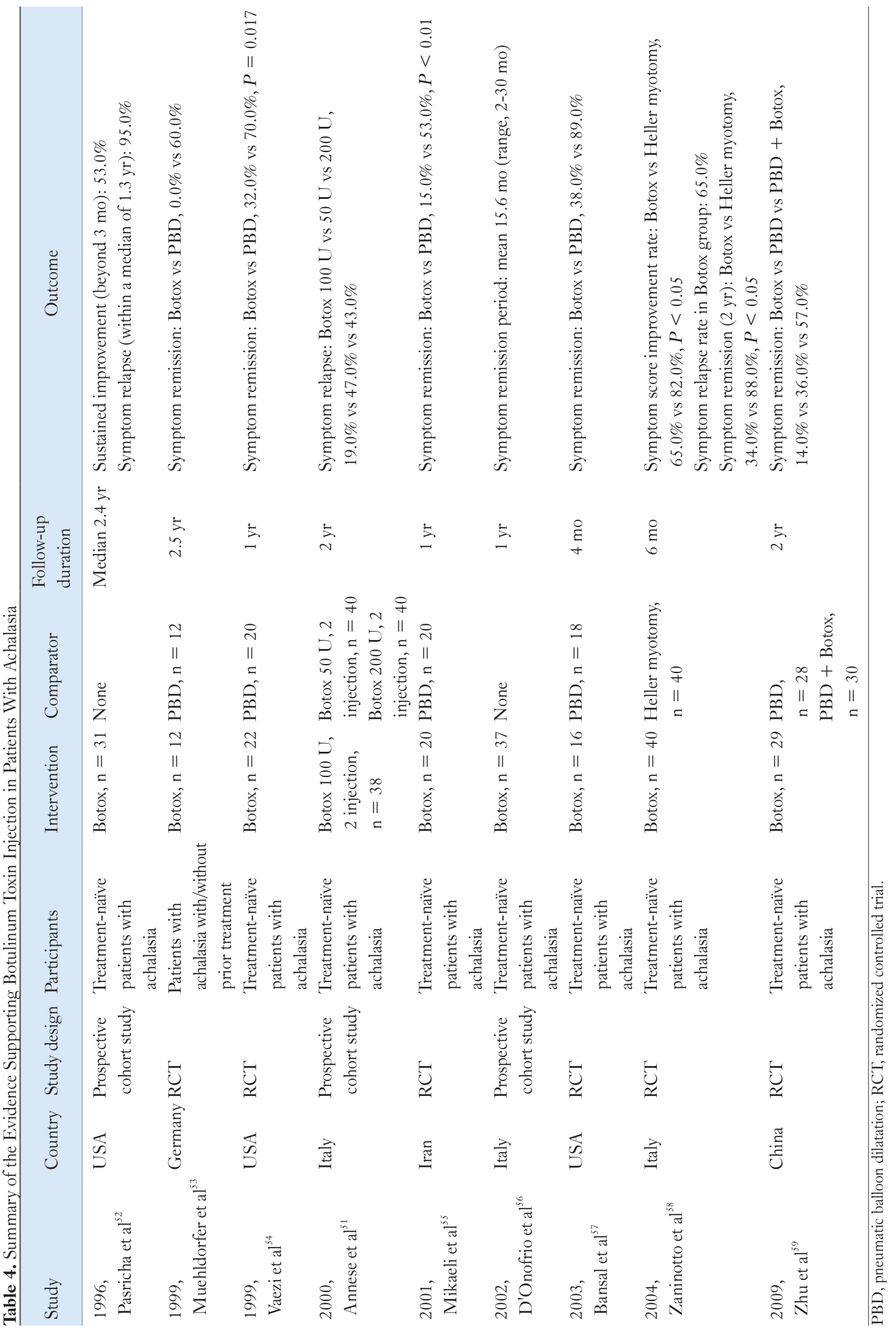




\section{Pneumatic balloon dilatation}

\section{Statement 11: Pneumatic balloon dilatation is recom- mended as an initial treatment for patients with achalasia.}

(Level of evidence, moderate; strength of recommendation, strong)

Experts' opinions: agree strongly (26.1\%), agree with some reservations (54.4\%), undecided (13.0\%), disagree (6.5\%), and disagree strongly $(0.0 \%)$

One of the most frequently used treatments for achalasia is PBD of the LES. ${ }^{59,64-72}$ Treatment parameters such as balloon size, number of dilations, inflation pressure, and duration vary according to the specialists or institutions. Depending on the general condition of the patient, graded PBD (with 30-mm, 35-mm, or 40-mm balloons) is considered one of the primary options for achalasia. ${ }^{73}$ According to a retrospective analysis of 209 patients, management of achalasia with initial dilation can provide good or excellent longterm results and high patient satisfaction rates. ${ }^{74} \mathrm{~A}$ prospective randomized European study of PBD and LHM reported that the therapeutic success rate was not significantly different between the 1 - and 2-year follow-ups $(P=0.46)$. Also, there was no significant difference in the pressure at the LES $(P=0.27)$ or esophageal emptying, as assessed by the height of the barium column $(P=$ 0.21) (Table 5). ${ }^{59,6472}$

\section{Peroral endoscopic myotomy}

\section{Statement 12: The outcomes of peroral endoscopic myotomy are comparable to those of laparoscopic Heller myotomy for treatment-naïve patients with achalasia.}

(Level of evidence, moderate; strength of recommendation, strong)

Experts' opinions: agree strongly (63.0\%), agree with some reservations $(37.0 \%)$, undecided $(0.0 \%)$, disagree $(0.0 \%)$, and disagree strongly $(0.0 \%)$

LHM is a first-line treatment for achalasia that achieved excellent outcomes in $91.8 \%$ of patients after a follow-up of 83.2 months. ${ }^{75,76}$ However, LHM is an invasive and expensive procedure that requires general anesthesia. ${ }^{77,78}$ Previous meta-analyses of POEM showed a clinical success rate of $98.0 \%{ }^{79,80}$ In meta-analysis of the present guidelines, the clinical efficacy rate of POEM was 92.8\% (95\% confidence interval [CI], 91.1-94.1\%) for the naive and prior treatment-failed patients combined, and $93.7 \%$ (95\% CI, 86.7-97.1\%) for naïve patients. Additionally, in another metaanalysis, the postoperative Eckardt score was better for patients who underwent POEM versus those who underwent LHM (Fig. 6). ${ }^{81}$

${ }^{86}$ Recent guidelines for achalasia stated that POEM has an efficacy similar to that of $\mathrm{LHM}^{87}$ A study with a 3-year follow-up showed that POEM was comparable to LHM in terms of the postoperative Eckardt score and quality of life. ${ }^{88} \mathrm{~A}$ large, recently published large cohort study, with long-term follow-up, showed that the clinical success rate of POEM was $87.0 \%$ after a median followup of 49 months. ${ }^{89}$ Reflux-related adverse events can occur with both POEM and LHM. However, in contrast to LHM, which requires partial fundoplication to reduce pathologic acid reflux, POEM is typically performed without any anti-reflux procedure. ${ }^{90}$ Previous meta-analyses reported that acid reflux occurs more frequently after POEM than after LHM. ${ }^{91,92}$ However, there was no difference in the rate of reflux symptoms, pathologic acid reflux, or the requirement for proton pump inhibitors (PPIs) between the POEM and LHM groups. ${ }^{84}$

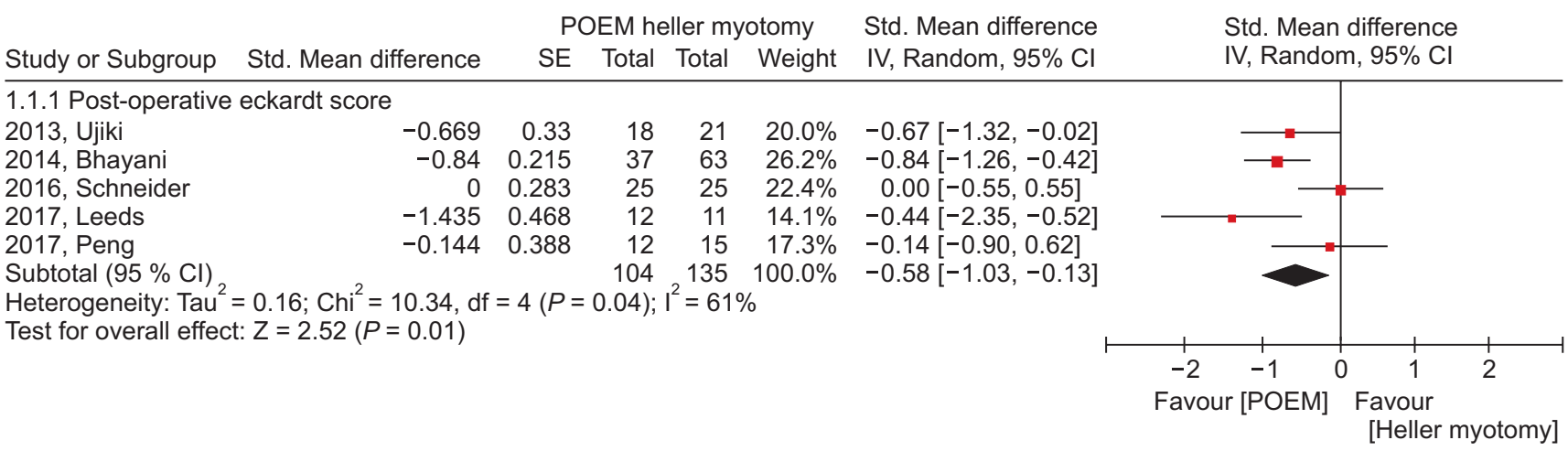

Figure 6. Meta-analysis comparing peroral endoscopic myotomy (POEM) and laparoscopic Heller myotomy (LHM). During the 3-year followup, POEM is comparable to LHM in terms of the postoperative Eckardt score. 


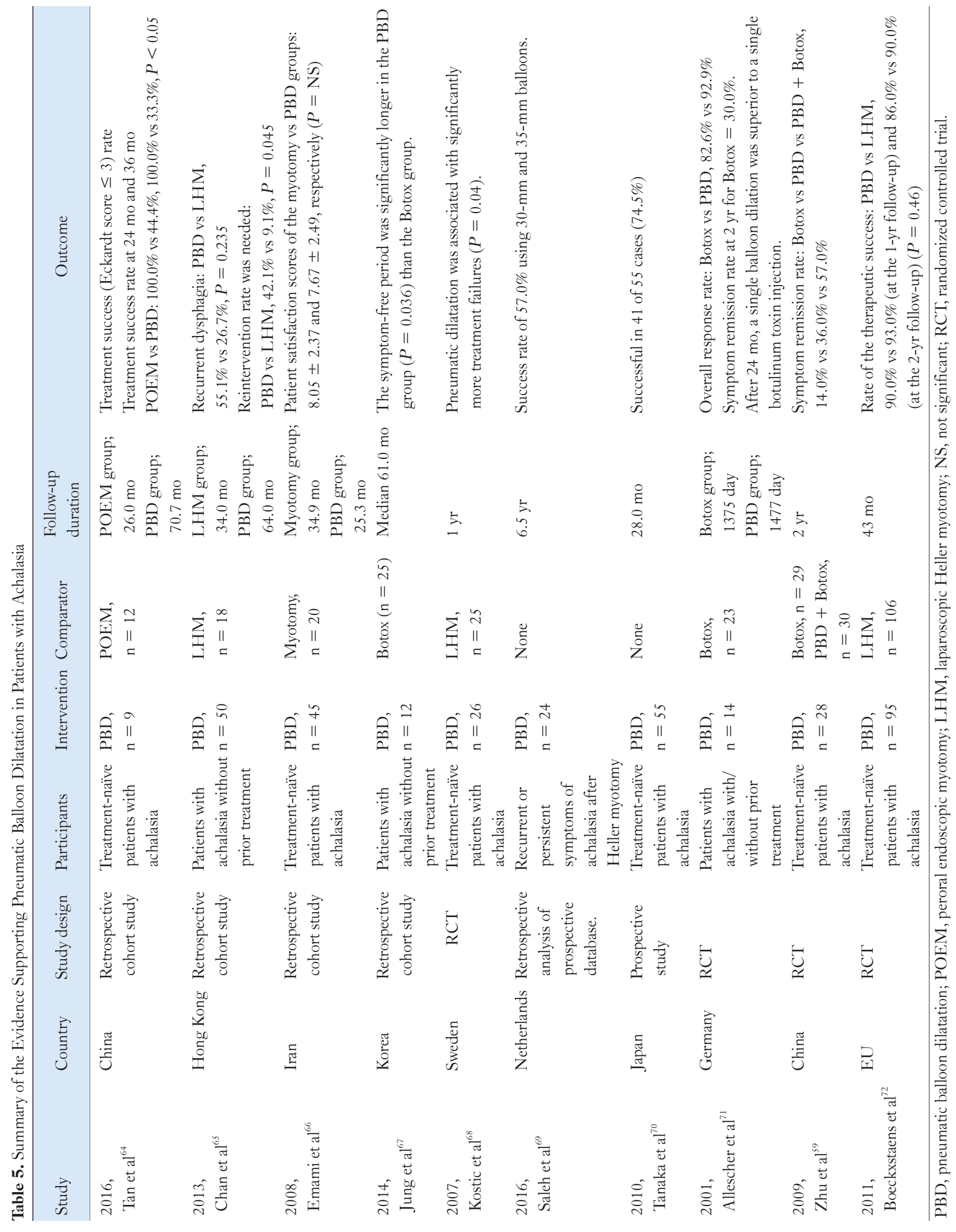


In summary, the high clinical efficacy of POEM, and the acceptable adverse event rate, are similar to those of LHM for treatment-naïve patients with achalasia. Nevertheless, long-term followup studies are required to define the role of POEM in the initial endoscopic treatment of achalasia.

\section{Statement 13: Peroral endoscopic myotomy, rather than laparoscopic Heller myotomy, can be considered for the treatment of type III achalasia because it can of- fer extended myotomy.}

(Level of evidence, low; strength of recommendation, weak)

Experts' opinions: agree strongly (43.4\%), agree with some reservations (37.0\%), undecided (17.4\%), disagree (2.2\%), and disagree strongly $(0.0 \%)$

Previous studies reported different success rates among the 3 achalasia subtypes; in particular, type III achalasia was associated with an increased risk of treatment failure compared to type II achalasia. ${ }^{22,23}$ Type III achalasia is characterized by pathological mechanisms involving the esophageal body and the LES. ${ }^{93}$ Therefore, the response rate to $\mathrm{PBD}$ or botulinum toxin injection is relatively low in patients with type III achalasia. In a study that reported treatment response according to achalasia subtype, the clinical success rate of the first session of PBD was 38.0\% (3/8) for type I achalasia, 73.0\% (19/26) for type II achalasia, and $0.0 \%$ (0/11) for type III achalasia. ${ }^{34}$ Botulinum toxin injection also showed low efficacy in patients with type III achalasia (type I, $0.0 \%$ [0/2]; type II, 86.0\% [6/7]; type III, $22.0 \%[2 / 9])$. In another study, the treatment response of PBD was $63.0 \%$ in type I achalasia, $90.0 \%$ in type II achalasia, and $33.0 \%$ in type III achalasia. ${ }^{24}$ Myotomy may have greater efficacy for the treatment of type III achalasia compared to PBD. A study involving 18 patients with type III achalasia demonstrated that LHM tended to have a clinical success rate superior to that of $\mathrm{PBD}$, although the difference was not significant $(86.0 \%$ vs $40.0 \%, P=0.12) .{ }^{94}$

Although the treatment response rate of type III achalasia patients undergoing LHM is higher than that of those undergoing PBD, the efficacy of LHM for type III achalasia is inferior to that for other types of achalasia. In a previous study on LHM in patients with achalasia, the clinical success rate was $85.0 \%, 95.0 \%$, and $70.0 \%$ for type I, type II, and type III achalasia, respectively $(P<$ $0.001){ }^{31}$

Unlike conventional treatments, such as PBD and LHM, POEM enables extended myotomy in patients with type III achalasia. Meta-analysis of studies comparing POEM and LHM showed that the length of myotomy was significantly greater for

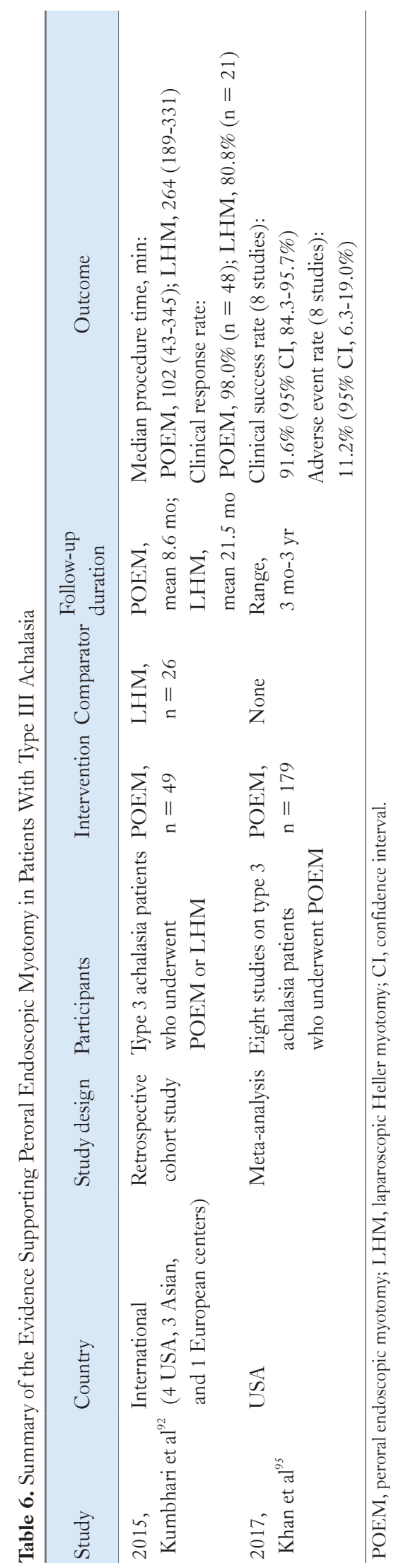


POEM than LHM. Also, operation time and length of hospital stay tended to be shorter for POEM than LHM. Another metaanalysis, of 8 studies on POEM for type III achalasia, demonstrated an overall clinical success rate of $91.6 \%$ (Table 6). ${ }^{92,95}$ Moreover, a multi-center retrospective cohort study including 75 patients with type III achalasia showed that the clinical response rate was higher in patients who underwent POEM than in those who underwent $\operatorname{LHM}(98.0 \%$ vs $81.0 \%, P=0.01){ }^{92}$

The overall rate of adverse events in type III achalasia patients who underwent POEM was $11.2 \%$ in the meta-analysis discussed above ${ }^{96}$ More than $70.0 \%$ of adverse events could be managed conservatively without further intervention. In some patients, the length of hospital stay was prolonged due to adverse events including pulmonary embolism, pneumothorax, capnoperitoneum, and bleeding. Inadvertent mucosotomies occurred in $3.0 \%$ of patients, who were managed by clipping. ${ }^{96}$ The rate of adverse events in patients with type III achalasia undergoing POEM seems to be acceptable.

Although large-scale randomized controlled trials (RCTs) are lacking, current evidence supports superior clinical efficacy of POEM over LHM in patients with type III achalasia, where the length of myotomy is greater for the former treatment modality. Given that, for patients with type III achalasia, the clinical success rate of POEM is good and the adverse event rate is acceptable, we recommend POEM over LHM for the treatment of type III achalasia.

\section{Statement 14: Acid suppressive therapy is recommend- ed for patients with reflux symptoms or esophageal erosion after peroral endoscopic myotomy, to prevent esophageal stricture.}

(Level of evidence, low; strength of recommendation, strong)

Experts' opinions: agree strongly (47.8\%), agree with some reservations $(50.0 \%)$, undecided $(2.2 \%)$, disagree $(0.0 \%)$, and disagree strongly $(0.0 \%)$

One of the main adverse events associated with POEM is gastroesophageal reflux. Unlike LHM, in POEM no anti-reflux procedure is performed; however, no alteration of the diaphragmatic and gastroesophageal anatomy occurs in POEM, which potentially reduces the risk of reflux. Gastroesophageal reflux is evaluated after POEM according to symptoms, $\mathrm{pH}$, and endoscopic findings. In meta-analysis of the present guidelines, the overall rates of reflux symptoms, abnormal $\mathrm{pH}$, and reflux esophagitis, according to endoscopic examinations, were $20.3 \%$ (95\% CI, 16.9-24.3\%), 24.7\% (95\% CI, 20.0-30.0\%), and $42.6 \%$ (95\% CI, 34.1-51.5\%), respec- tively. However, there is no significant difference of development of GERD between POEM and LHM (Fig. 7).

Although the definitions of symptoms, abnormal $\mathrm{pH}$, and abnormal endoscopic findings were not standardized across the studies, POEM is clearly associated with an increased risk of postprocedural reflux. Therefore, acid suppressive therapy is recommended after POEM for patients with reflux symptom or esophagitis. Also, there is a dissociation among the rate of abnormal acid exposure and the rates of reflux symptoms and reflux esophagitis based on endoscopic examinations. Therefore, clinicians should evaluate asymptomatic patients via regular endoscopy examinations or $\mathrm{pH}$ monitoring.

In a previous meta-analysis, the rate of PPI use after POEM ranged from $2.6 \%$ to $27.8 \%$ (pooled estimate, $10.6 \%$; 95\% CI, 6.517.3\%). ${ }^{90}$ However, the optimal duration and dose of PPI use are controversial. Most patients with post-procedural gastroesophageal reflux can be treated using a standard PPI dose. Also, the longterm effects of an abnormal $\mathrm{pH}$ in asymptomatic participants are unclear. Therefore, a short course of PPIs is recommended after POEM, although a more tailored approach based on symptoms, $\mathrm{pH}$ and endoscopy findings appears to be more appropriate.

\section{Surgical Treatment}

\section{Statement 15: Laparoscopic Heller myotomy can be considered a first-line therapy for achalasia patients, and has similar expected clinical outcomes to pneu- matic balloon dilation.}

(Level of evidence, moderate; strength of recommendation, weak)

Experts' opinions: agree strongly (18.2\%), agree with some reservations (75.8\%), undecided (3.0\%), disagree (3.0\%), and disagree strongly $(0.0 \%)$

Surgical myotomy, also known as Heller myotomy, disrupts the muscle fibers of the LES. LHM is the preferred surgical technique because of its low morbidity rate and the rapid rate of recovery. ${ }^{97.98}$ In a systematic review involving 3086 patients, symptom improvement after LHM was achieved in $89.3 \%$ after a mean of 35.4 months (range: 8-83 months). ${ }^{97}$ Two prospective, randomized trials have compared PBD and LHM. ${ }^{99,100}$ Although LHM was more effective for symptom relief, these were small, low-quality trials and one failed to meet its recruitment target. Borges et $\mathrm{al}^{101}$ reported that LHM and PBD for achalasia were equally effective, even at the 2-year follow-up. In a large, high-quality, multicenter randomized trial involving 201 patients, there was no significant 


\begin{tabular}{|l|l|}
\hline Patients with achalasia & $\begin{array}{l}\text { This recommendation applies to almost all patients with achalasia } \\
\text { - Patients dignosed using conventional or high resolution } \\
\text { manometry } \\
\text { - Treatment-naive patients or patients who failed to the } \\
\text { prior treatment }\end{array}$ \\
\begin{tabular}{|l|l|} 
However the recommendation is not applicable to patients with: \\
- Sigmoid achalasia \\
- Surgically high-risk patients
\end{tabular} \\
\hline
\end{tabular}

Comparison of benefits and harms

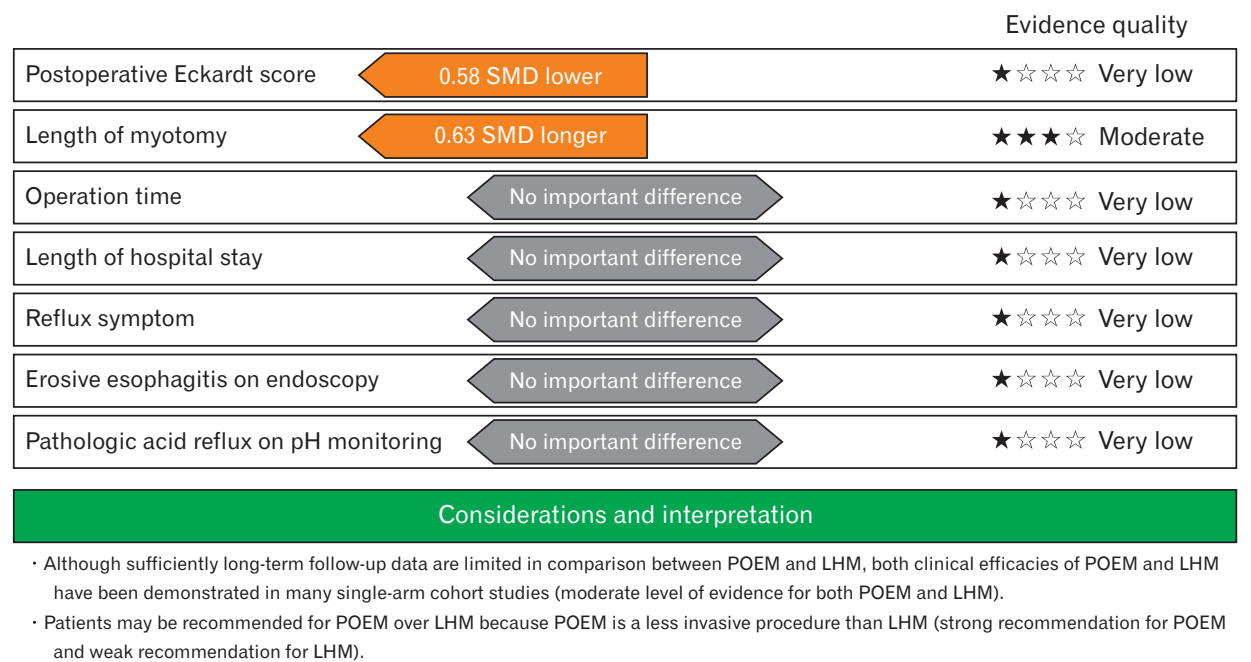

Figure 7. Comparison of peroral endoscopic myotomy and laparoscopic Heller myotomy in patients with achalasia. POEM, peroral endoscopic myotomy; SMD, standard mean difference; LHM, laparoscopic Heller myotomy.

difference in treatment success rate after 1,2 , and 5 years of followup. $^{25,72}$ Rohof et $\mathrm{al}^{94}$ reported differences in outcomes according to the achalasia subtype. The success rate of PBD was significantly higher than that of LHM for type II achalasia (100.0\% vs $93.0 \%$, $P<0.05) .{ }^{94}$ However, the largest difference in symptom remission rates between PBD and LHM was observed in type III achalasia, although the difference was not statistically significant due to the small number of patients in this subgroup. In addition, type III achalasia patients treated by PBD had significantly greater esophageal stasis compared to type III patients treated by LHM. Therefore, patients with type III seem to respond better to LHM than to PBD. However, RCTs comparing the outcomes of LHM and PBD in the various achalasia subtypes are needed to draw definitive conclusions. It should also be noted that PBD is a more cost-effective treatment option than LHM for achalasia. ${ }^{102,103}$

\section{Statement 16: Partial fundoplication in addition to $\mathrm{LHM}$ is recommended to reduce the risk of subsequent GERD.}

(Level of evidence, low; strength of recommendation, strong) Experts' opinions: agree strongly (23.9\%), agree with some reservations $(56.5 \%)$, undecided $(17.4 \%)$, disagree $(2.2 \%)$, and disagree strongly $(0.0 \%)$

The antireflux barrier function of the LES is lost after myotomy, and the need to add an antireflux procedure to LHM has long been debated. In a meta-analysis, the rate of gastroesophageal reflux symptoms was reduced when fundoplication was added to myotomy $(8.8 \%$ vs $31.5 \%, P=0.001){ }^{97}$ However, the rate of postoperative dysphagia was higher after LHM plus Nissen fundoplication than after LHM plus Dor fundoplication (15.0\% vs $2.8 \%$, $P=0.001) .{ }^{104}$ In contrast, the relief of dysphagia after LHM plus Dor fundoplication was shown to be comparable to LHM alone. ${ }^{105}$ In addition, 2 types of partial fundoplication (Dor and Toupet) were 
comparable in terms of the degree of improvement in symptoms after LHM. ${ }^{106}$ Partial fundoplication reportedly decreases reflux after LHM. ${ }^{107}$ Finley et $\mathrm{al}^{108}$ reported no difference in the frequency or severity of reflux symptoms between patients with and without anterior fundoplication. However, that study was limited by the significant difference in preoperative upright esophageal clearance between the 2 groups. To draw definitive conclusions, additional large randomized trials are needed.

\section{Management of Achalasia Recurrence After Initial Treatment}

If $\mathrm{PBD}$ fails as a first-line treatment, additional treatment with PBD may be considered. ${ }^{67,109} \mathrm{PBD}$ is also an option when symptoms recur after botulinum toxin injection. ${ }^{69}$ In cases showing persistent or recurrent symptoms after LHM, retreatment with PBD may be considered. ${ }^{110,111}$ LHM is an effective treatment for the majority of achalasia patients. However, a small proportion of patients suffer persistent or recurrent symptoms after surgery. In such cases, the success rate of PBD after surgery was reported to vary from $50.0 \%$ to $78.0 \%{ }^{108-110}$ If the symptoms persist after POEM, PBD may be considered as salvage therapy depending on the clinical symptoms of the patient, although there are relatively few studies supporting this. ${ }^{75,76,112}$

\section{Statement 17: Peroral endoscopic myotomy is recom- mended for achalasia patients who failed initial endo- scopic treatment.}

(Level of evidence, moderate; strength of recommendation, strong)

Experts' opinions: agree strongly (60.9\%), agree with some reservations $(34.8 \%)$, undecided $(4.3 \%)$, disagree $(0.0 \%)$, and disagree strongly $(0.0 \%)$

The endoscopic treatment options for achalasia treatment with durable outcomes are PBD and POEM. Although PBD showed a long-term success rate of 72.0-86.0\%, re-dilation was required by up to one-third of patients with recurrent symptoms. ${ }^{25,70,72,75}$ Young age, residual LES pressure $>10 \mathrm{mmHg}$, stasis on TBE, and male sex have been reported as predictive factors for symptom recurrence after PBD. ${ }^{113-114}$ POEM is a treatment option in cases for which PBD failed, as well as an initial treatment for achalasia (Table 7). ${ }^{77,109,115-122}$ Large-scale observational studies including patients in whom PBD failed have reported that POEM is a safe and effective treatment option. ${ }^{96,117,120}$ Prior treatment did not increase the risk of POEM-related adverse events. ${ }^{116,119,120}$ However, patients with prior treatment showed a longer procedure time and higher rate of clinical failure after POEM compared to those without prior treatment. ${ }^{120}$ POEM has a reported efficacy rate of $>90 \%$ based on short-term follow-up data. Persistence or recurrence of symptoms may occur after POEM. Two studies showed that redo POEM is feasible for patients in whom POEM failed, as a salvage option with a $100.0 \%$ technical success rate and an $85.0-100.0 \%$ clinical success rate based on short-term follow-up data. ${ }^{121,122}$ For patients with persistent or recurrent symptoms after POEM, redo POEM seems to be an efficacious and safe technique. ${ }^{123}$

In summary, POEM appears to be a safe and effective option for patients who failed initial endoscopic treatment. Long-term follow-up and randomized studies comparing other treatment options are required to define the role of POEM for cases of achalasia in which initial endoscopic treatment failed.

Statement 18: Peroral endoscopic myotomy can be considered as a rescue treatment for achalasia patients who were not treated successfully by Heller myotomy.

(Level of evidence, low; strength of recommendation, weak)

Experts' opinions: agree strongly $(28.3 \%)$, agree with some reservations (47.8\%), undecided $(17.4 \%)$, disagree (6.5\%), and disagree strongly $(0.0 \%)$

Recurrent or persistent symptoms occurred in about 10.0$20.0 \%$ of patients who underwent LHM. $^{25}$ For such patients, treatment options include repeat LHM, PD, or POEM. Recently, POEM has been used as a rescue treatment for patients who failed LHM. Clinical studies have reported success rates of 92.098.0\%. ${ }^{124-126}$ Thus, POEM could be a feasible salvage treatment for patients with persistent symptoms after LHM. However, additional large studies with longer follow-up periods are necessary.

\section{Esophagectomy}

In patients with end-stage achalasia, when repeated endoscopic or surgical treatments are not effective, some patients may require esophagectomy to relieve their symptoms. Indeed, the presence of a megaesophagus (maximum esophageal diameter $>6 \mathrm{~cm}$ ), could be a predictive factor for the need of esophagectomy. ${ }^{127-129}$ In a recent systemic review, the postoperative morbidity ranged from $19.0 \%$ to $50.0 \%$ and the mortality ranged from $0.0 \%$ to $5.4 \%{ }^{129}$ Given the high morbidity and mortality, esophagectomy should be performed in patients with a megaesophagus who are fit for major surgery, complain of long-lasting disabling symptoms not responding to multiple endoscopic and surgical interventions, preferably in specialized centers. 


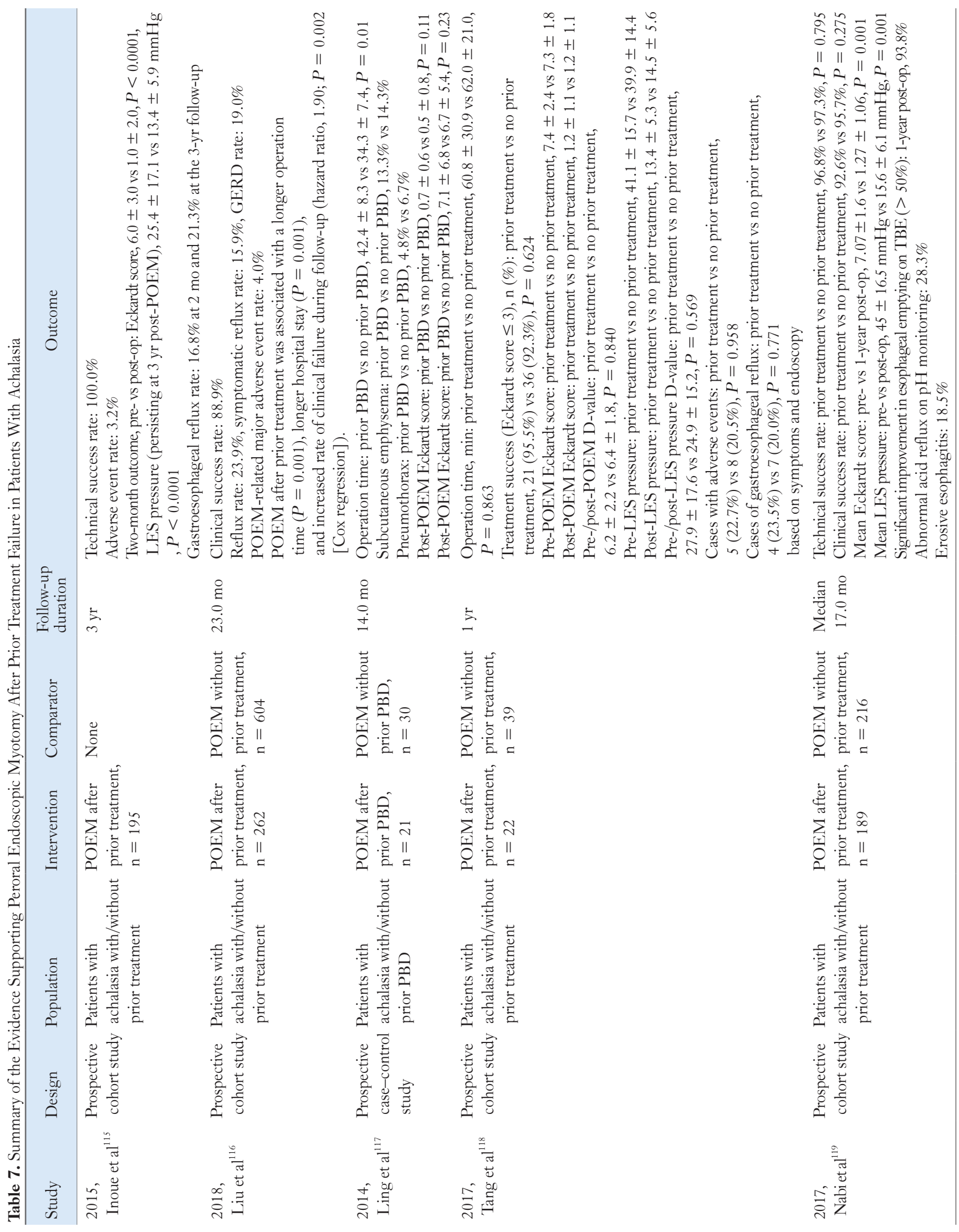




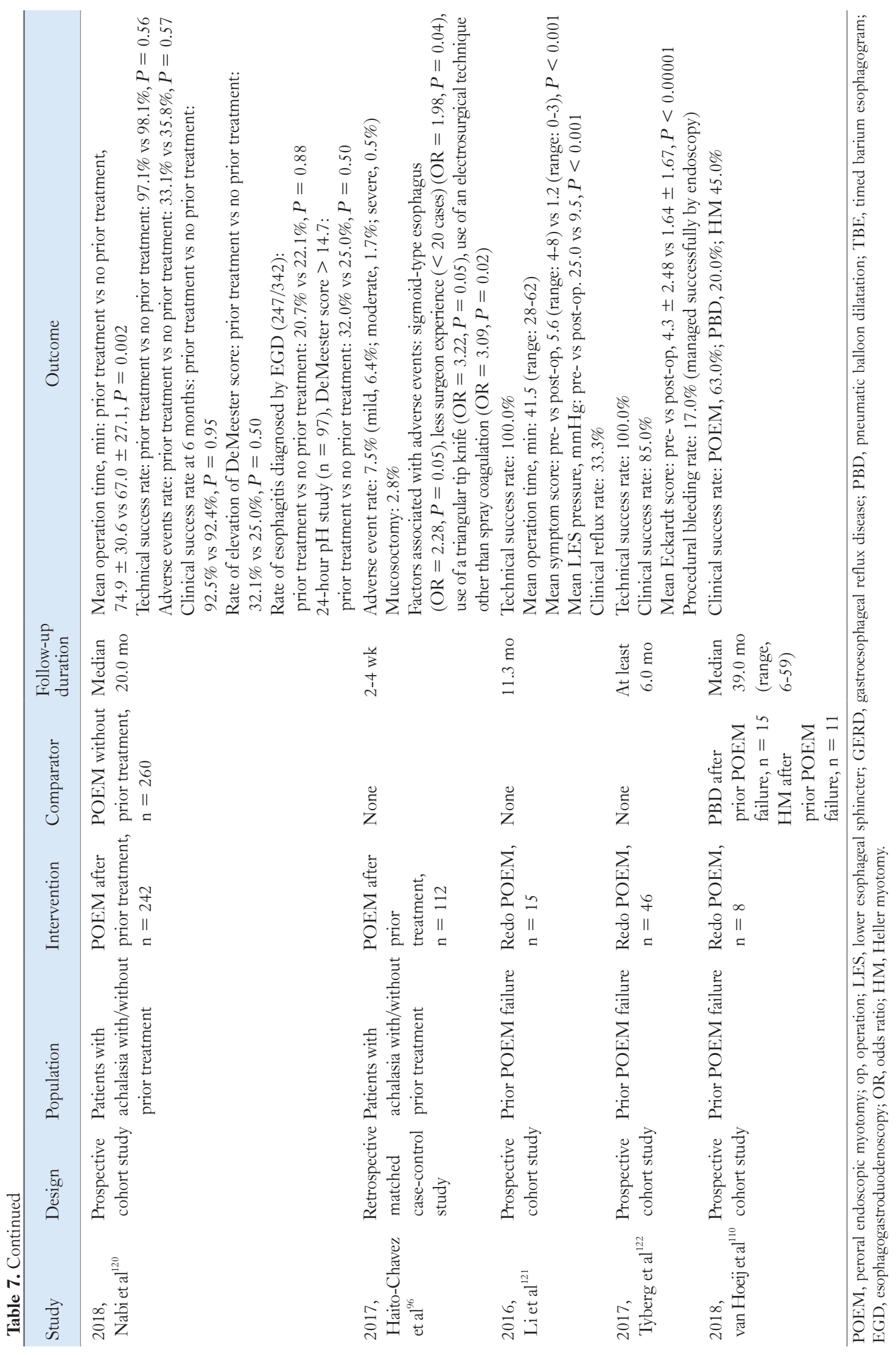




\section{Conclusions}

The 2019 Seoul Consensus on Esophageal Achalasia Guidelines for esophageal achalasia introduced herein are designed to serve as a practical, evidence-based guide for clinicians (including primary physicians, gastroenterologists, upper GI tract surgeons, medical students, nurses, and paramedical teams) and patients. Esophageal manometry is the gold standard for diagnosing achalasia, while the Chicago classification for HRM is useful for defining the clinically relevant phenotypes of achalasia. Endoscopic management (PBD or POEM) and LHM show similar efficacy with respect to the initial management of achalasia. POEM can serve as both an initial and rescue therapy for patients with achalasia, and may be the preferred option for patients with type III achalasia. The present guidelines will be updated periodically in response to new evidence. Prospective studies of the long-term therapeutic outcomes of PBD, POEM, and LHM, including their benefits and harm, are needed.

\section{Supplementary Material}

Note: To access the supplementary figure mentioned in this article, visit the online version of Journal of Neurogastroenterology and Motility at http://www.jnmjournal.org/, and at https://doi. org/10.5056/jnm20014.

Acknowlegements: We are grateful to all who participated in this study. We thank Young-Tae Bak (South Korea) and Sutep Gonlachanvit (Thailand) for external review. In addition, we also thank Prof. Mi-Young Choi for helping us develop the guidelines as a methodologist and literature search.

\section{Financial support: None.}

\section{Conflicts of interest: None.}

Author contributions: Hye-Kyung Jung, Su Jin Hong, and Oh Young Lee have contributed in writing and editing the paper as the first author and the corresponding author; John Pandolfino, Hyojin Park, Hiroto Miwa, Uday C Ghoshal, Sanjiv Mahadeva, Tadayuki Oshima, Minhu Chen, Andrew S B Chua, Yu Kyung Cho, Tae Hee Lee, Sung Eun Kim, Yang Won Min, Chan Hyuk Park, Joong Goo Kwon, Moo In Park, Kyoungwon Jung, Jong Kyu Park, Kee Wook Jung, Hyun Chul Lim, Da Hyun Jung, Do Hoon Kim, Chul-Hyun Lim, Hee Seok Moon, Jung Ho Park, Suck Chei Choi, Hidekazu Suzuki, Tanisa Patcharatrakul, Justin C
Y Wu, Kwang Jae Lee, Shinwa Tanaka, and Kewin T H Siah have contributed in the systematic review, the extraction of recommendations, and writing the paper; Chan Hyuk Park, Da Hyun Jung, Do Hoon Kim, Chul-Hyun Lim, Hee Seok Moon, and Su Jin Hong performed the meta-analysis; and Hye-Kyung Jung and Oh Young Lee have designed the development of guideline as the chairman of the guideline committee and KSNM.

\section{References}

1. Vaezi MF, Pandolfino JE, Vela MF. ACG clinical guideline: diagnosis and management of achalasia. Am J Gastroenterol 2013;108:1238-1249.

2. Jones J, Hunter D. Consensus methods for medical and health services research. BMJ 1995;311:376-380.

3. Higgins JP, Altman DG, Gøtzsche PC, et al. The Cochrane collaboration's tool for assessing risk of bias in randomised trials. BMJ 2011;343:d5928.

4. Schünemann H, Brożek J, Guyatt G, Oxman AD. GRADE handbook: handbook for grading the quality of evidence and the strength of recommendations using the GRADE approach. Hamilton, CA: The GRADE Working Group 2013.

5. Song KH, Jung HK, Kim HJ, et al. Clinical practice guidelines for irritable bowel syndrome in Korea, 2017 revised edition. J Neurogastroenterol Motil 2018;24:197-215.

6. Goldblum JR, Rice TW, Richter JE. Histopathologic features in esophagomyotomy specimens from patients with achalasia. Gastroenterology 1996;111:648-654.

7. Kessing BF, Bredenoord AJ, Smout AJ. Erroneous diagnosis of gastroesophageal reflux disease in achalasia. Clin Gastroenterol Hepatol 2011;9:1020-1024.

8. Tracey JP, Traube M. Difficulties in the diagnosis of pseudoachalasia. Am J Gastroenterol 1994;89:2014-2018.

9. van Hoeij FB, Ponds FA, Smout AJ, Bredenoord AJ. Incidence and costs of achalasia in The Netherlands. Neurogastroenterol Motil 2018;30:e13195.

10. Stein CM, Gelfand M, Taylor HG. Achalasia in Zimbabwean blacks. S Afr MED J 1985;67:261-262.

11. Tebaibia A, Boudjella MA, Boutarene D, Benmediouni F, Brahimi $\mathrm{H}$, Oumnia N. Incidence, clinical features and para-clinical findings of achalasia in Algeria: experience of 25 years. World J Gastroenterol 2016;22:8615-8623.

12. Samo S, Carlson DA, Gregory DL, Gawel SH, Pandolfino JE, Kahrilas PJ. Incidence and prevalence of achalasia in central Chicago, 2004-2014, since the widespread use of high-resolution manometry. Clin Gastroenterol Hepatol 2017;15:366-373.

13. Sadowski DC, Ackah F, Jiang B, Svenson LW. Achalasia: incidence, prevalence and survival. A population-based study. Neurogastroenterol Motil 2010;22:e256-e261.

14. Kim E, Lee H, Jung HK, Lee KJ. Achalasia in Korea: an epidemiologic study using a national healthcare database. J Korean Med Sci 2014;29:576-580. 
15. Enestvedt BK, Williams JL, Sonnenberg A. Epidemiology and practice patterns of achalasia in a large multi-centre database. Aliment Pharmacol Ther 2011;33:1209-1214.

16. O'Neill OM, Johnston BT, Coleman HG. Achalasia: a review of clinical diagnosis, epidemiology, treatment and outcomes. World J Gastroenterol 2013;19:5806-5812.

17. Moonen A, Boeckxstaens G. Current diagnosis and management of achalasia. J Clin Gastroenterol 2014;48:484-490.

18. Moonen AJ, Boeckxstaens GE. Management of achalasia. Gastroenterol Clin North Am 2013;42:45-55.

19. Kahrilas PJ, Bredenoord AJ, Fox M, et al. The Chicago classification of esophageal motility disorders, v3.0. Neurogastroenterol Motil 2015;27:160-174.

20. Pandolfino JE, Ghosh SK, Rice J, Clarke JO, Kwiatek MA, Kahrillas PJ. Classifying esophageal motility by pressure topography characteristics: a study of 400 patients and 75 controls. Am J Gastroenterol 2008;103:2737.

21. Roman S, Huot L, Zerbib F, et al. High-resolution manometry improves the diagnosis of esophageal motility disorders in patients with dysphagia: a randomized multicenter study. Am J Gastroenterol 2016;111:372-380.

22. Oude Nijhuis RAB, Prins LI, Mostafavi N, van Etten-Jamaludin FS, Smout AJPM, Bredenoord AJ. Factors associated with achalasia treatment outcomes: systematic review and meta-analysis. Clin Gastroenterol Hepatol 2019 (In press).

23. Pandolfino JE, Kwiatek MA, Nealis T, Bulsiewicz W, Post J, Kahrilas PJ. Achalasia: a new clinically relevant classification by high-resolution manometry. Gastroenterology 2008;135:1526-1533.

24. Pratap N, Kalapala R, Darisetty S, et al. Achalasia cardia subtyping by high-resolution manometry predicts the therapeutic outcome of pneumatic balloon dilatation. J Neurogastroenterol Motil 2011;17:48-53.

25. Moonen A, Annese V, Belmans A, et al. Long-term results of the European achalasia trial: a multicentre randomised controlled trial comparing pneumatic dilation versus laparoscopic heller myotomy. Gut 2016;65:732739.

26. Rosen MJ, Novitsky YW, Cobb WS, Kercher KW, Heniford BT. Laparoscopic heller myotomy for achalasia in 101 patients: can successful symptomatic outcomes be predicted? Surg Innov 2007;14:177-183.

27. Salvador R, Costantini M, Cavallin F, et al. Laparoscopic heller myotomy can be used as primary therapy for esophageal achalasia regardless of age. J Gastrointest Surg 2014;18:106-111; discussion 112.

28. Salvador R, Savarino E, Pesenti E, et al. Effects of laparoscopic myotomy on the esophageal motility pattern of esophageal achalasia as measured by high-resolution manometry. Surg Endosc 2017;31:3510-3518.

29. Yamashita H, Ashida K, Fukuchi T, et al. Predictive factors associated with the success of pneumatic dilatation inJapanese patients with primary achalasia: a study using high-resolution manometry. Digestion 2013;87:23-28.

30. Ren Y, Tang X, Chen Y, et al. Pre-treatment Eckardt score is a simple factor for predicting one-year peroral endoscopic myotomy failure in patients with achalasia. Surg Endosc 2017;31:3234-3241.

31. Salvador R, Costantini M, Zaninotto G, et al. The preoperative manometric pattern predicts the outcome of surgical treatment for esophageal achalasia. J Gastrointest Surg 2010;14:1635-1645.

32. Levine MS, Rubesin SE, Laufer I. Barium esophagography: a study for all seasons. Clin Gastroenterol Hepatol 2008;6:11-25.

33. Levine MS. Ten questions about barium esophagography and dysphagia. Gastroenterol Clin North Am 2018;47:449-473.

34. Rohof WO, Lei A, Boeckxstaens GE. Esophageal stasis on a timed barium esophagogram predicts recurrent symptoms in patients with longstanding achalasia. Am J Gastroenterol 2013;108:49-55.

35. Andersson M, Lundell L, Kostic S, et al. Evaluation of the response to treatment inpatients with idiopathic achalasia by the timed barium esophagogram: results from a randomized clinical trial. Dis Esophagus 2009;22:264-273.

36. Blonski W, Kumar A, Feldman J, Richter JE. Timed barium swallow: diagnostic role and predictive value in untreated achalasia, esophagogastric junction outflow obstruction, and non-achalasia dysphagia. Am J Gastroenterol 2018;113:196-203.

37. Stavropoulos SN, Friedel D, Modayil R, Parkman HP. Diagnosis and management of esophageal achalasia. BMJ 2016;354:i2785.

38. Ponds FA, van Raath MI, Mohamed SMM, Smout AJPM, Bredenoord AJ. Diagnostic features of malignancy-associated pseudoachalasia. Aliment Pharmacol Ther 2017;45:1449-1458.

39. Abubakar U, Bashir MB, Kesieme EB. Pseudoachalasia: a review. Niger J Clin Pract 2016;19:303-307.

40. Vaezi MF, Felix VN, Penagini R, et al. Achalasia: from diagnosis to management. Ann NY Acad Sci 2016;1381:34-44.

41. Howard PJ, Maher L, Pryde A, Cameron EW, Heading RC. Five year prospective study of the incidence, clinical features, and diagnosis of achalasia in Edinburgh. Gut 1992;33:1011-1015.

42. Pandolfino JE, Gawron AJ. Achalasia: a systematic review. JAMA 2015;313:1841-1852

43. Vaezi MF, Richter JE. Diagnosis and management of achalasia. American college of gastroenterology practice parameter committee. Am J Gastroenterol 1999;94:3406-3412.

44. Bortolotti M, Coccia G, Brunelli F, et al. Isosorbide dinitrate or nifedipine: which is preferable in the medical therapy of achalasia? Ital J Gastroenterol 1994;26:379-382.

45. Bortolotti M, Labò G. Clinical and manometric effects of nifedipine in patients with esophageal achalasia. Gastroenterology 1981;80:39-44.

46. Coccia G, Bortolotti M, Michetti P, Dodero M. Prospective clinical and manometric study comparing pneumatic dilatation and sublingual nifedipine in the treatment of oesophageal achalasia. Gut 1991;32:604-606.

47. Hongo M, Traube M, McAllister RG Jr, McCallumRW. Effects of nifedipine on esophageal motor function in humans: correlation with plasma nifedipine concentration. Gastroenterology 1984;86:8-12.

48. Bassotti G, Annese V. Review article: pharmacological options in achalasia. Aliment Pharmacol Ther 1999;13:1391-1396.

49. Marzio L, Grossi L, DeLaurentiis MF, Cennamo L, Lapenna D, Cuccurullo F. Effect of cimetropium bromide on esophageal motility and transit in patients affected by primary achalasia. Dig Dis Sci 1994;39:1389-1394

50. Annese V, Basciani M, Perri F, et al. Controlled trial of botulinum toxin injection versus placebo and pneumatic dilation in achalasia. Gastroenter- 
ology 1996;111:1418-1424.

51. Annese V, Bassotti G, Coccia G, et al. A multicentre randomised study of intrasphincteric botulinum toxin in patients with oesophageal achalasia. GISMAD achalasia study group. Gut 2000;46:597-600.

52. Pasricha PJ, Rai R, Ravich WJ, Hendrix TR, Kalloo AN. Botulinum toxin for achalasia: long-term outcome and predictors of response. Gastroenterology 1996;110:1410-1415.

53. Muehldorfer SM, Schneider TH, Hochberger J, Martus P, Hahn EG, Ell C. Esophageal achalasia: intrasphincteric injection of botulinum toxin A versus balloon dilation. Endoscopy 1999;31:517-521.

54. Vaezi MF, Richter JE, Wilcox CM, et al. Botulinum toxin versus pneumatic dilatation in the treatment of achalasia: a randomised trial. Gut 1999;44:231-239.

55. Mikaeli J, Fazel A, Montazeri G, Yaghoobi M, Malekzadeh R. Randomized controlled trial comparing botulinum toxin injection to pneumatic dilatation for the treatment of achalasia. Aliment Pharmacol Ther 2001;15:1389-1396.

56. D’Onofrio V, Miletto P, Leandro G, Iaquinto G. Long-term followup of achalasia patients treated with botulinum toxin. Dig Liver Dis 2002;34:105-110.

57. Bansal R, Nostrant TT, Scheiman JM, et al. Intrasphincteric botulinum toxin versus pneumatic balloon dilation for treatment of primary achalasia. J Clin Gastroenterol 2003;36:209-214.

58. Zaninotto G, Annese V, Costantini M, et al. Randomized controlled trial of botulinum toxin versus laparoscopic heller myotomy for esophageal achalasia. Ann Surg 2004;239:364-370.

59. Zhu Q, Liu J, Yang C. Clinical study on combined therapy of botulinum toxin injection and small balloon dilation in patients with esophageal achalasia. Dig Surg 2009;26:493-498.

60. Vela MF, Richter JE, Wachsberger D, Conor J, Rice TW. Complexities of managing achalasia at a tertiary referral center: use of pneumatic dilatation, heller myotomy, and botulinum toxin injection. Am J Gastroenterol 2004;99:1029-1036.

61. Chao CY, Raj A, Saad N, Hourigan L, Holtmann G. Esophageal perforation, inflammatory mediastinitis and pseudoaneurysm of the thoracic aorta as potential complications of botulinum toxin injection for achalasia. Dig Endosc 2015;27:618-621.

62. van Hoeij FB, Tack JF, Pandolfino JE, et al. Complications of botulinum toxin injections for treatment of esophageal motility disorders $\dagger$. Dis Esophagus 2017;30:1-5

63. Martínek J, Siroký M, PlottováZ, et al. Treatment of patients with achalasia with botulinum toxin: a multicenter prospective cohort study. Dis Esophagus 2003;16:204-209.

64. Tan Y, Zhu H, Li C, Chu Y, Huo J, Liu D. Comparison of peroral endoscopic myotomy and endoscopic balloon dilation for primary treatment of pediatric achalasia. J Pediatr Surg 2016;51:1613-1618.

65. Chan SM, Chiu PW, Wu JC, et al. Laparoscopic heller's cardiomyotomy achieved lesser recurrent dysphagia with better quality of life when compared with endoscopic balloon dilatation for treatment of achalasia. Dis Esophagus 2013;26:231-236.

66. Emami MH, Raisi M, Amini J, et al. Pneumatic balloon dilation therapy is as effective as esophagomyotomy for achalasia. Dysphagia
2008;23:155-160.

67. Jung HE, Lee JS, Lee TH, et al. Long-term outcomes of balloon dilation versus botulinum toxin injection in patients with primary achalasia. Korean J Intern Med 2014;29:738-745.

68. Kostic S, Kjellin A, Ruth M, et al.Pneumatic dilatation or laparoscopic cardiomyotomy in the management of newly diagnosed idiopathic achalasia. Results of a randomized controlled trial. World J Surg 2007;31:470478.

69. Saleh CM, Ponds FA, Schijven MP, Smout AJ, Bredenoord AJ. Efficacy of pneumodilation in achalasia after failed heller myotomy. Neurogastroenterol Motil 2016;28:1741-1746.

70. Tanaka Y, Iwakiri K, Kawami N, et al. Predictors of a better outcome of pneumatic dilatation in patients with primary achalasia. J Gastroenterol 2010;45:153-158.

71. Allescher HD, Storr M, Seige M, et al. Treatment of achalasia: botulinum toxin injection vs. pneumatic balloon dilation. A prospective study with long-term follow-up. Endoscopy 2001;33:1007-1017.

72. Boeckxstaens GE, Annese V, des Varannes SB, et al. Pneumatic dilation versus laparoscopic heller's myotomy for idiopathic achalasia. N Engl J Med 2011;364:1807-1816.

73. van Hoeij FB, Prins LI, Smout AJPM, Bredenoord AJ. Efficacy and safety of pneumatic dilation in achalasia: a systematic review and metaanalysis. Neurogastroenterol Motil 2019;31:e13548.

74. Hulselmans M, Vanuytsel T, Degreef T, et al. Long-term outcome of pneumatic dilation in the treatment of achalasia. Clin Gastroenterol Hepatol 2010;8:30-35.

75. Boeckxstaens GE, Zaninotto G, Richter JE. Achalasia. Lancet 2014;383:83-93.

76. Rossetti G, Brusciano L, Amato G, et al. A total fundoplication is not an obstacle to esophageal emptying after heller myotomy for achalasia: results of a long-term follow up. Ann Surg 2005;241:614-621.

77. Malagelada JR, Bazzoli F, Boeckxstaens G, et al. World gastroenterology organisation global guidelines: dysphagia--global guidelines and cascades update September 2014. J Clin Gastroenterol 2015;49:370-378.

78. Ramchandani M, Nageshwar Reddy D, Nabi Z, etal. Management of achalasia cardia: expert consensus statements. J Gastroenterol Hepatol 2018;33:1436-1444

79. Crespin OM, Liu LWC, Parmar A, et al. Safety and efficacy of POEM for treatment of achalasia: a systematic review of the literature. Surg Endosc 2017;31:2187-2201.

80. Akintoye E, Kumar N, Obaitan I, Alayo QA, Thompson CC. Peroral endoscopic myotomy: a meta-analysis. Endoscopy 2016;48:1059-1068.

81. Park CH, Jung DH, Kim DH, et al. Comparative efficacy of per-oral endoscopic myotomy and heller myotomy in patients with achalasia: a meta-analysis. Gastrointest Endosc 2019;90:546-558.e3.

82. Bhayani NH, Kurian AA, Dunst CM, Sharata AM, Rieder E, Swanstrom LL. A comparative study on comprehensive, objective outcomes of laparoscopic heller myotomy with per-oral endoscopic myotomy (POEM) for achalasia. Ann Surg 2014;259:1098-1103.

83. Leeds SG, Burdick JS, Ogola GO, Ontiveros E. Comparison of outcomes of laparoscopic heller myotomy versus per-oral endoscopic myotomy for management of achalasia. Proc (Bayl Univ Med Cent) 
2017;30:419-423.

84. Schneider AM, Louie BE, Warren HF, Farivar AS, Schembre DB, Aye RW. A matched comparison of per oral endoscopic myotomy to laparoscopic heller myotomy in the treatment of achalasia. J Gastrointest Surg 2016;20:1789-1796.

85. Ujiki MB, Yetasook AK, Zapf M, Linn JG, Carbray JM, Denham W. Peroral endoscopic myotomy: a short-term comparison with the standard laparoscopic approach. Surgery 2013;154:893-897; discussion 897-900.

86. Peng L, Tian S, Du C, Yuan Z, Guo M, Lu L. Outcome of peroral endoscopic myotomy (POEM) for treating achalasia compared with laparoscopic heller myotomy (LHM). Surg Laparosc Endosc Percutan Tech 2017;27:60-64.

87. Zaninotto G, Bennett C, Boeckxstaens G, et al. The 2018 ISDE achalasia guidelines. Dis Esophagus Online First: 30 Aug 2018. doi: 10.1093/ dote/doy071.

88. Li QL, Wu QN, Zhang XC, et al. Outcomes of per-oral endoscopic myotomy for treatment of esophageal achalasia with a median follow-up of 49 months. Gastrointest Endosc 2018;87:1405-1412, e3.

89. de Pascale S, Repici A, Puccetti F, Carlani E, Rosati R, Fumagalli U. Peroral endoscopic myotomy versus surgical myotomy for primary achalasia: single-center, retrospective analysis of 74 patients. Dis Esophagus 2017;30:1-7.

90. Repici A, Fuccio L, Maselli R, et al. GERD after per-oral endoscopic myotomy as compared with heller's myotomy with fundoplication: a systematic review with meta-analysis. Gastrointest Endosc 2018;87:934943, e18.

91. Schlottmann F, Luckett DJ, Fine J, shaheen NJ, Patti MG. Laparoscopic heller myotomy versus peroral endoscopic myotomy (POEM) for achalasia: a systematic review and meta-analysis. Ann Surg 2018;267:451460 .

92. Kumbhari V, Tieu AH, Onimaru M, et al. Peroral endoscopic myotomy (POEM) vs laparoscopic heller myotomy (LHM) for the treatment of type III achalasia in 75 patients: a multicenter comparative study. Endosc Int Open 2015;3:E195-E201.

93. Gregersen H, Lo KM. Pathophysiology and treatment of achalasia in a muscle mechanical perspective. Ann N Y Acad Sci 2018;1434:173-184.

94. Rohof WO, Salvador R, Annese V, et al. Outcomes of treatment for achalasia depend on manometric subtype. Gastroenterology 2013;144:718725 .

95. Khan MA, Kumbhari V, Ngamruengphong S, et al. Is POEM the answer for management of spastic esophageal disorders? A systematic review and meta-analysis. Dig Dis Sci 2017;62:35-44.

96. Haito-Chavez Y, Inoue H, Beard KW, et al. Comprehensive analysis of adverse events associated with per oral endoscopic myotomy in 1826 patients: an international multicenter study. Am J Gastroenterol 2017;112:1267-1276.

97. Campos GM, Vittinghoff E, Rabl C, et al. Endoscopic and surgical treatments for achalasia: a systematic review and meta-analysis. Ann Surg 2009;249:45-57

98. Ali A, Pellegrini CA. Laparoscopic myotomy: technique and efficacy in treating achalasia. Gastrointest Endosc Clin N Am 2001;11:347-358, vii.

99. Persson J, Johnsson E, Kostic S, Lundell L, Smedh U. Treatment of achalasia with laparoscopic myotomy or pneumatic dilatation: long-term results of a prospective, randomized study. World J Surg 2015;39:713720 .

100. Hamdy E, El Nakeeb A, El Hanfy E, et al. Comparative study between laparoscopic heller myotomy versus pneumatic dilatation for treatment of early achalasia: a prospective randomized study. J Laparoendosc Adv Surg Tech A 2015;25:460-464.

101. Borges AA, Lemme EM, Abrahao LJ Jr, et al. Pneumatic dilation versus laparoscopic heller myotomy for the treatment of achalasia: variables related to a good response. Dis Esophagus 2014;27:18-23.

102. Kostic S, Johnsson E, Kjellin A, et al. Health economic evaluation of therapeutic strategies in patients with idiopathic achalasia: results of a randomized trial comparing pneumatic dilatation with laparoscopic cardiomyotomy. Surg Endosc 2007;21:1184-1189.

103. Karanicolas PJ, Smith SE, Inculet RI, et al. The cost of laparoscopic myotomy versus pneumatic dilatation for esophageal achalasia. Surg Endosc 2007;21:1198-1206

104. Rebecchi F, Giaccone C, Farinella E, Campaci R, Morino M. Randomized controlled trial of laparoscopic heller myotomy plus dor fundoplication versus nissen fundoplication for achalasia: long-term results. Ann Surg 2008;248:1023-1030.

105. Richards WO, Torquati A, Holzman MD, et al. Heller myotomy versus heller myotomy with dor fundoplication for achalasia: a prospective randomized double-blind clinical trial. Ann Surg 2004;240:405-12; discussion 412-415.

106. Rawlings A, Soper NJ, Oelschlager B, et al.Laparoscopic dor versus toupet fundoplication following heller myotomy for achalasia: results of a multicenter, prospective, randomized-controlled trial. Surg Endosc 2012;26:18-26.

107. Tapper D, Morton C, Kraemer E, et al. Does concomitant anterior fundoplication promote dysphagia after laparoscopic heller myotomy? Am Surg 2008;74:626-633; discussion 633-634.

108. Finley C, Clifton J, Yee J, Finley RJ. Anterior fundoplication decreases esophageal clearance in patients undergoing heller myotomy for achalasia. Surg Endosc 2007;21:2178-2182.

109. Stewart RD, Hawel J, French D, Bethune D, Ellsmere J. S093: pneumatic balloon dilation for palliation of recurrent symptoms of achalasia after esophagomyotomy. Surg Endosc 2018;32:4017-4021.

110.van Hoeij FB, Ponds FA, Werner Y, et al. Management of recurrent symptoms after per-oral endoscopic myotomy in achalasia. Gastrointest Endosc 2018;87:95-101.

111.Xu MM, Kahaleh M. Recurrent symptoms after per-oral endoscopic myotomy in achalasia: redo, dilate, or operate? a call for a tailored approach. Gastrointest Endosc 2018;87:102-103.

112. Nabi Z, Reddy DN, Ramchandani M. Retreatment after failure of peroral endoscopic myotomy: does "cutting" fare better than "stretching"? Gastrointest Endosc 2017;86:927-928.

113. Ghoshal UC, Rangan M, Misra A. Pneumatic dilation for achalasia cardia: reduction in lower esophageal sphincter pressure in assessing response and factors associated with recurrence during long-term follow up. Dig Endosc 2012;24:7-15.

114. Ghoshal UC, Kumar S, Saraswat VA, Aggarwal R, Misra A, Choudhuri 
G. Long-term follow-up after pneumatic dilation for achalasia cardia: factors associated with treatment failure and recurrence. Am J Gastroenterol 2004;99:2304-2310.

115. Inoue $\mathrm{H}$, Sato $\mathrm{H}$, Ikeda H, et al. Per-oral endoscopic myotomy: a series of 500 patients. J Am Coll Surg 2015;221:256-264.

116. Liu ZQ, Li QL, Chen WF, et al. The effect of prior treatment on clinical outcomes in patients with achalasia undergoing peroral endoscopic myotomy. Endoscopy 2019;51:307-316.

117. Ling T, Guo H, Zou X. Effect of peroral endoscopic myotomy in achalasia patients with failure of prior pneumatic dilation: a prospective casecontrol study. J Gastroenterol Hepatol 2014;29:1609-1613.

118. Tang X, Gong W, Deng Z, et al. Feasibility and safety of peroral endoscopic myotomy for achalasia after failed endoscopic interventions. Dis Esophagus 2017;30:1-6.

119. Nabi Z, Ramchandani M, Chavan R, et al. Per-oral endoscopic myotomy for achalasia cardia: outcomes in over 400 consecutive patients. Endosc Int Open 2017;5:E331-E339.

120. Nabi Z, Ramchandani M, Chavan R, et al. Peroral endoscopic myotomy in treatment-naïve achalasia patients versus prior treatment failure cases. Endoscopy 2018;50:358-370.

121.Li QL, Yao LQ, Xu XY, et al. Repeat peroral endoscopic myotomy: a salvage option for persistent/recurrent symptoms. Endoscopy 2016;48:134-140.

122. Tyberg A, Seewald S, Sharaiha RZ, et al. A multicenter international registry of redo per-oral endoscopic myotomy (POEM) after failed POEM. Gastrointest Endosc 2017;85:1208-1211.

123.Zhou PH, Li QL, Yao LQ, et al. Peroral endoscopic remyotomy for failed heller myotomy: a prospective single-center study. Endoscopy 2013;45:161-166.

124. Ngamruengphong S, Inoue H, Ujiki MB, et al. Efficacy and safety of peroral endoscopic myotomy for treatment of achalasia after failed heller myotomy. Clin Gastroenterol Hepatol 2017;15:1531-1537, e3.

125.Zhang X, Modayil RJ, Friedel D, et al. Per-oral endoscopic myotomy in patients with or without prior heller's myotomy: comparing long-term outcomes in a large U.S. single-center cohort (with videos). Gastrointest Endosc 2018;87:972-985.

126. Tyberg A, Sharaiha RZ, Familiari P, et al. Peroral endoscopic myotomy as salvation technique post-heller: international experience. Dig Endosc 2018;30:52-56.

127.Eldaif SM, Mutrie CJ, Rutledge WC, et al. The risk of esophageal resection after esophagomyotomy for achalasia. Ann Thorac Surg 2009;87:1558-1562; discussion 1562-1563.

128. Loviscek MF, Wright AS, Hinojosa MW, et al. Recurrent dysphagia after heller myotomy: is esophagectomy always the answer? J Am Coll Surg 2013;216:736-743; discussion 743-744.

129. Aiolfi A, Asti E, Bonitta G, Bonavinal L. Esophagectomy for endstage achalasia: systematic review and meta-analysis. World J Surg 2018;42:1469-1476. 